Article

\title{
Screening of Bioactive Metabolites and Biological Activities of Calli, Shoots, and Seedlings of Mertensia maritima (L.) Gray
}

\author{
Kihwan Song ${ }^{1}$, Iyyakkannu Sivanesan ${ }^{2, *}\left(\mathbb{D}\right.$, Gunes Ak $^{3}$, Gokhan Zengin ${ }^{3}{ }^{(D}$, Zoltán Cziáky ${ }^{4}(\mathbb{D}$, \\ József Jekő ${ }^{4}$, Kannan RR Rengasamy ${ }^{5,6,7}$, O New Lee ${ }^{8}$ and Doo Hwan Kim ${ }^{2}$ \\ 1 Department of Bioresources Engineering, Sejong University, 209 Neungdong-ro, Gwangjin-gu, \\ Seoul 05006, Korea; khsong@sejong.ac.kr \\ 2 Department of Bioresources and Food Science, Institute of Natural Science and Agriculture, \\ Konkuk University, Seoul 05029, Korea; kimdh@konkuk.ac.kr \\ 3 Department of Biology, Faculty of Science, Selcuk University, 42130 Konya, Turkey; \\ akguneselcuk@gmail.com (G.A.); gokhanzengin@selcuk.edu.tr (G.Z.) \\ 4 Agricultural and Molecular Research and Service Institute, University of Nyíregyháza, \\ 4400 Nyíregyháza, Hungary; cziaky.zoltan@nye.hu (Z.C.); jjozsi@gmail.com (J.J.) \\ 5 Institute of Research and Development, Duy Tan University, Da Nang 550000, Vietnam; \\ rengasamyrrajakannan@duytan.edu.vn \\ 6 Faculty of Environment and Chemical Engineering, Duy Tan University, Da Nang 550000, Vietnam \\ 7 Indigenous Knowledge Systems Centre, Faculty of Natural and Agricultural Sciences, \\ North-West University, Private Bag X2046, Mmabatho 2745, North West Province, South Africa \\ 8 Department of Bioindustry and Bioresource Engineering, Sejong University, 209 Neungdong-ro, \\ Gwangjin-gu, Seoul 05006, Korea; onewlee@sejong.ac.kr \\ * Correspondence: siva74@konkuk.ac.kr; Tel.: +82-2450-0576
}

Received: 29 October 2020; Accepted: 11 November 2020; Published: 12 November 2020

\begin{abstract}
Mertensia maritima (L.) Gray is threatened with extinction owing to climate change, poor seed germination, and ocean warming. In vitro explant-culture is used for ex situ preservation and plantlet massive production. In vitro cell and organ cultures serve as an alternative plant material source to investigate the biological activities and phytochemical profiles of rare plants. We aimed to develop an efficient callus and shoot production protocol and investigate bioactive metabolites, antioxidants, and enzyme inhibitory potential of M. maritima calli, shoots, and in vivo seedlings. The effects of combinations of different plant growth regulators, 6-BA ( $\mathrm{N}^{6}$-benzyladenine), 6-KN (Kinetin), TDZ (Thidiazuron), and NAA (1-Naphthylacetic acid), in MS (Murashige and Skoog) nutrient medium were studied. The highest callus proliferation was obtained after 5 -week cultivation over a 16-h photoperiod on growth medium MS enriched with $4 \mu \mathrm{M}$ each of 6-BA and NAA. The medium with $2 \mu \mathrm{M} 6-\mathrm{BA}$ and $4 \mu \mathrm{M} 6-\mathrm{KN}$ had the best shoot induction rate (91.1\%) with a mean of 13.4 shoots. The combination of two cytokinins (6-BA and 6-KN) was found to be effective in M. maritima shoot regeneration. The rooting frequency was $100 \%$ in $\frac{1}{2}$ MS with Indole-3-butyric acid (IBA $2 \mu \mathrm{M}$ ). The number of detected compounds and chemical composition in the M. maritima shoots and seedlings extracts were similar. The total amount of phenolics in the shoots was $216.4 \%$ and $369.5 \%$ higher than in seedlings and calli, respectively. The total amount of flavonoids in the shoots was $241.1 \%$ and $429.3 \%$ higher than in seedlings and calli, respectively. The best antioxidant activity was obtained in the shoots, followed by seedlings and calli. However, the order was seedlings $>$ calli $>$ shoots regarding metal chelating ability. The strongest acetylcholinesterase inhibition properties were obtained in the calli, followed by seedlings and shoots. However, the tested samples can be ranked as seedlings $>$ shoots > calli in butylcholinestrase inhibition assay. This study is the first report on the enzyme inhibitory effects of M. maritima extracts, providing valuable contributions to the scientific community.
\end{abstract}


Keywords: axillary shoot multiplication; antioxidant activity; conservation; plant growth regulators; enzyme inhibition; flavonoids; phenolics

\section{Introduction}

The genus Mertensia of the family Boraginaceae comprises 62 species of perennial herbs widely distributed in Europe, North and Central America, and Northern Asia [1]. Several Mertensia species are traditionally used to treat tuberculosis, venereal diseases, and whooping cough [2]. Pyrrolizidine alkaloids such as lycopsamine and intermedine were found in M. bakeri (Greene) and M. ciliata (James) G. Don [3]. M. maritima (L.) Gray, also recognized as an oyster plant, is largely found in the northern hemisphere. It has striking blue-green leaves and blooms from June to September with pink and blue flowers; thus, it has high ornamental value. The fresh leaves, taproots, and flowers of M. maritima are eaten by the Iñupiat of Alaska [2]. However, the presence of hepatotoxic pyrrolizidine alkaloids in the tissues of M. maritima has not yet been disclosed. It contains several bioactive metabolites such as carotenoids, phenolic acid, terpenoids, tocopherol, fatty acids, and volatile compounds [4-6], which are well-known to have many biological activities. In addition, the pharmacological activities of Mertensia species have not yet been documented.

M. maritima is at risk of extinction owing to climate change and ocean warming [7]. Although the cultivation of oyster plants in nurseries is often difficult [7], it has been successfully grown in southwestern France and Northern Scotland [4]. M. maritima is naturally propagated by seeds. However, the mass production of M. maritima using conventional methods is hampered because of its poor seed germination. Therefore, an alternative mass production method for M. maritima would be valuable. In vitro explant-culture methods are effectively used for ex situ germplasm maintenance and the massive production of plantlets and bioactive metabolites. Recently, the in vitro micropropagation of M. maritima was reported [6]; the authors used TDZ (Thidiazuron) for micropropagation. However, the mass production of healthy M. maritima shoots is affected by TDZ. Continuous TDZ exposure resulted in shoot tip necrosis and hyperhydricity (Figure 1a,b). Hence, the identification of an efficient plant growth regulator (PGR) is necessary for the in vitro multiplication of M. maritima shoots.
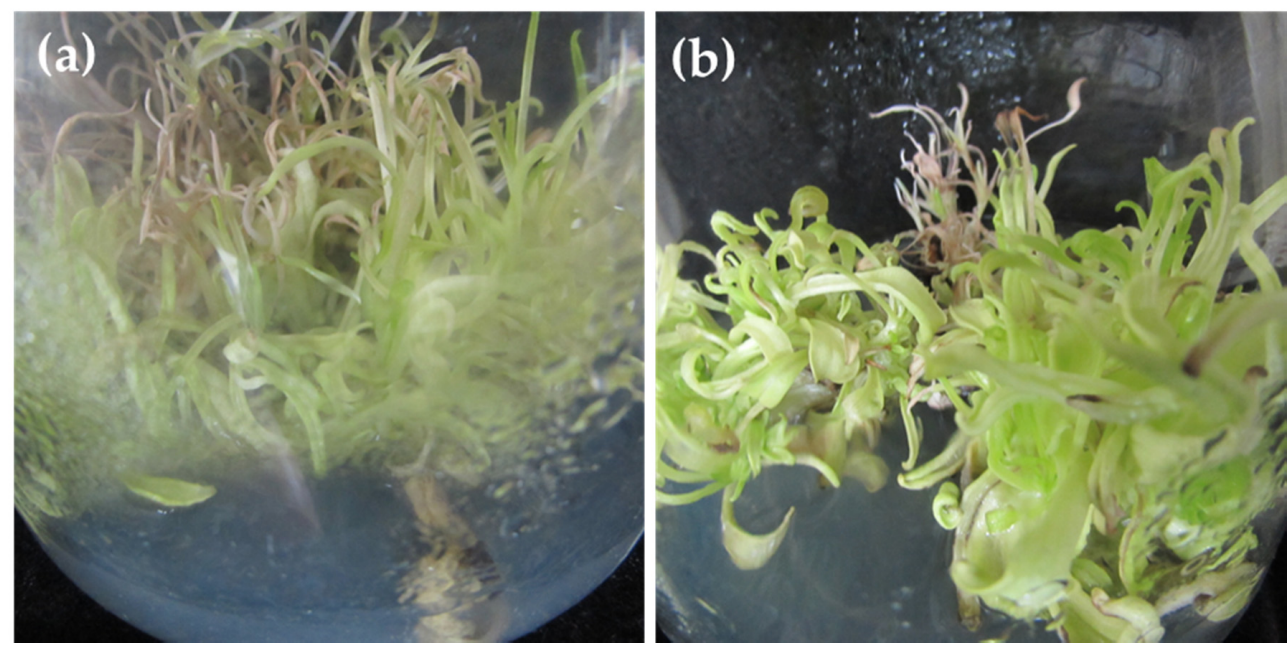

Figure 1. (a) Shoot tip necrosis occurred after 5-week cultivation over a 16-h photoperiod in a culture medium containing MS (Murashige and Skoog) + $1 \mu \mathrm{M}$ NAA (1-Naphthylacetic acid) + $4 \mu \mathrm{M}$ TDZ (Thidiazuron) [6]. (b) Hyperhydricity occurred after 5-week cultivation over a 16-h photoperiod in a culture medium containing MS $+1 \mu \mathrm{M}$ NAA $+2 \mu \mathrm{M}$ TDZ [6].

Several bioactive metabolites such as allantoin, rabdosiin, rosmarinic acid, all-E-lutein, all-E- $\beta$-carotene, all- $E$-violaxanthin, 9-Z-neoxanthin, $(Z)-\beta$-carotene, all-E-zeaxanthin, $\alpha$-tocopherol, 
$\alpha$-linolenic acid, palmitic acid, linoleic acid, $\gamma$-linolenic acid, stearidonic acid, stearic acid, lignoceric acid, behenic acid, and arachidic acid were obtained from M. maritima callus and shoot cultures $[5,6]$. However, the screening of bioactive metabolites, including phenolics, in M. maritima calli, shoots, and in vivo seedlings, has not yet been reported. Thus, the aims of this work were to (a) determine the effects of PGRs on callus and shoot proliferation, (b) assess the bioactive metabolite profile of in vitro-developed calli and shoots and in vivo seedlings, and (c) estimate the antioxidant capacity and enzyme inhibitory activity of M. maritima.

\section{Results}

\subsection{In Vitro Propagation}

\subsubsection{Callus Induction}

Leaf explants of M. maritima inoculated on control medium (MS medium devoid of hormones) failed to develop calli after 5 weeks of cultivation. Calli were induced in the inoculated explants on medium with combinations of 6-BA ( $\mathrm{N}^{6}$-benzyladenine) and NAA (2-(1-naphthyl) acetic acid) (Figure 2a). Callus initiation was detected within 2 weeks of cultivation. Of the six different combinations of 6-BA and NAA studied, $4 \mu \mathrm{M}$ of each 6-BA and NAA was found to be the most useful for callusing with $89.6 \%$ frequency (Figure 3a). Calli induced on this media thrived compared with those induced using other treatments; therefore, the above medium was selected to study callus growth. The lowest percentage of callus initiation (44.7\%) was noticed in the medium with $2 \mu \mathrm{M}$ of 6-BA and NAA (Figure 2a). Light green, friable calli obtained from leaf explants of M. maritima were inoculated on medium containing 6-BA and NAA each at $4 \mu \mathrm{M}$, and growth was monitored at weekly intervals up to 7 weeks. The growth of $M$. maritima calli displayed a normal sigmoidal curve having log, lag, and stationary phases from 0 to 1,1 to 5 , and 5 to 7 weeks, respectively. The results disclosed that the biomass of the callus intensified slowly with an increase in the cultivation period. The maximum fresh weight (FW) and dry weight (DW) of the calli were obtained after 5 and 6 weeks of cultivation, respectively (Figure $2 b$ ).

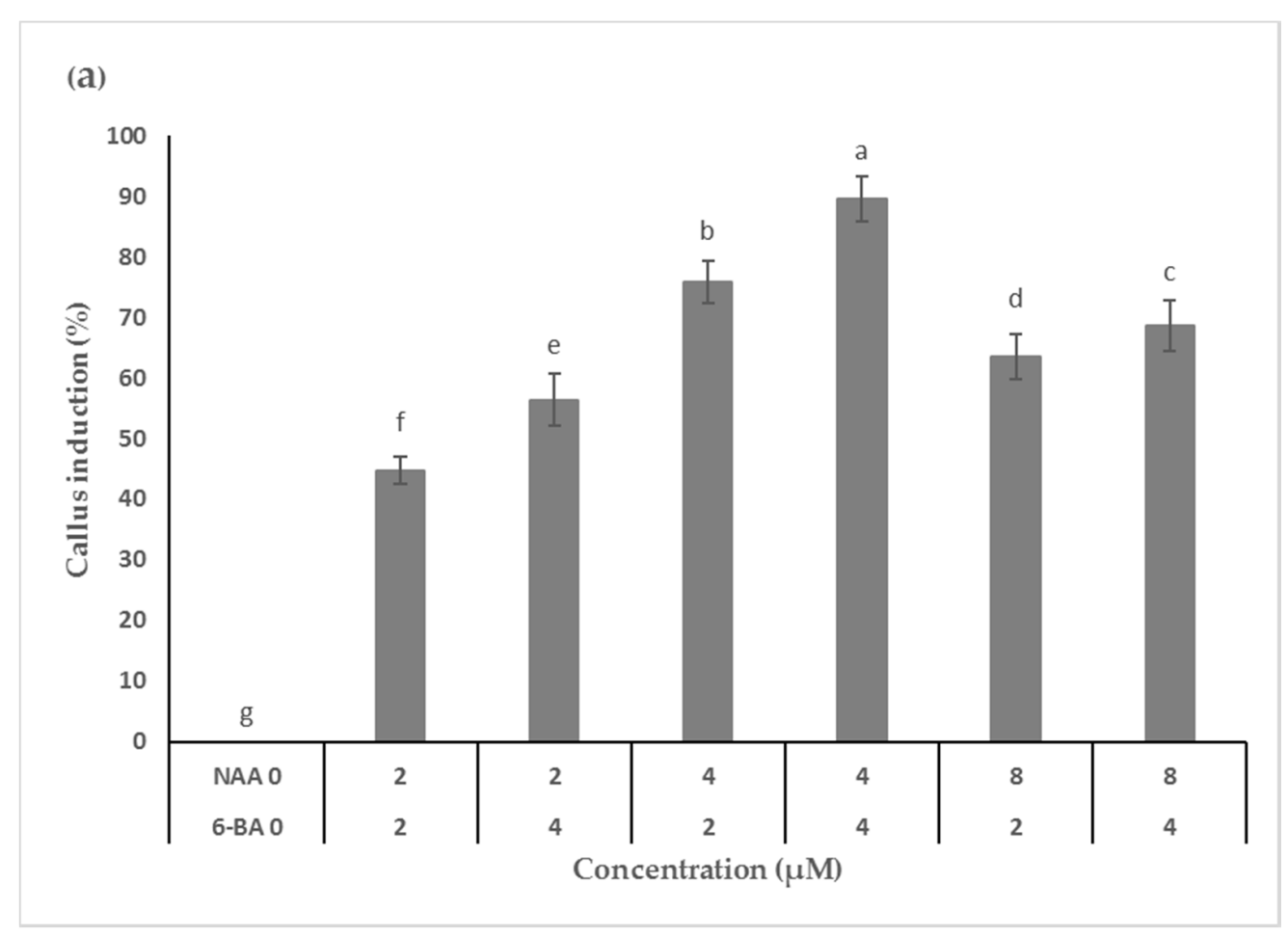

Figure 2. Cont. 


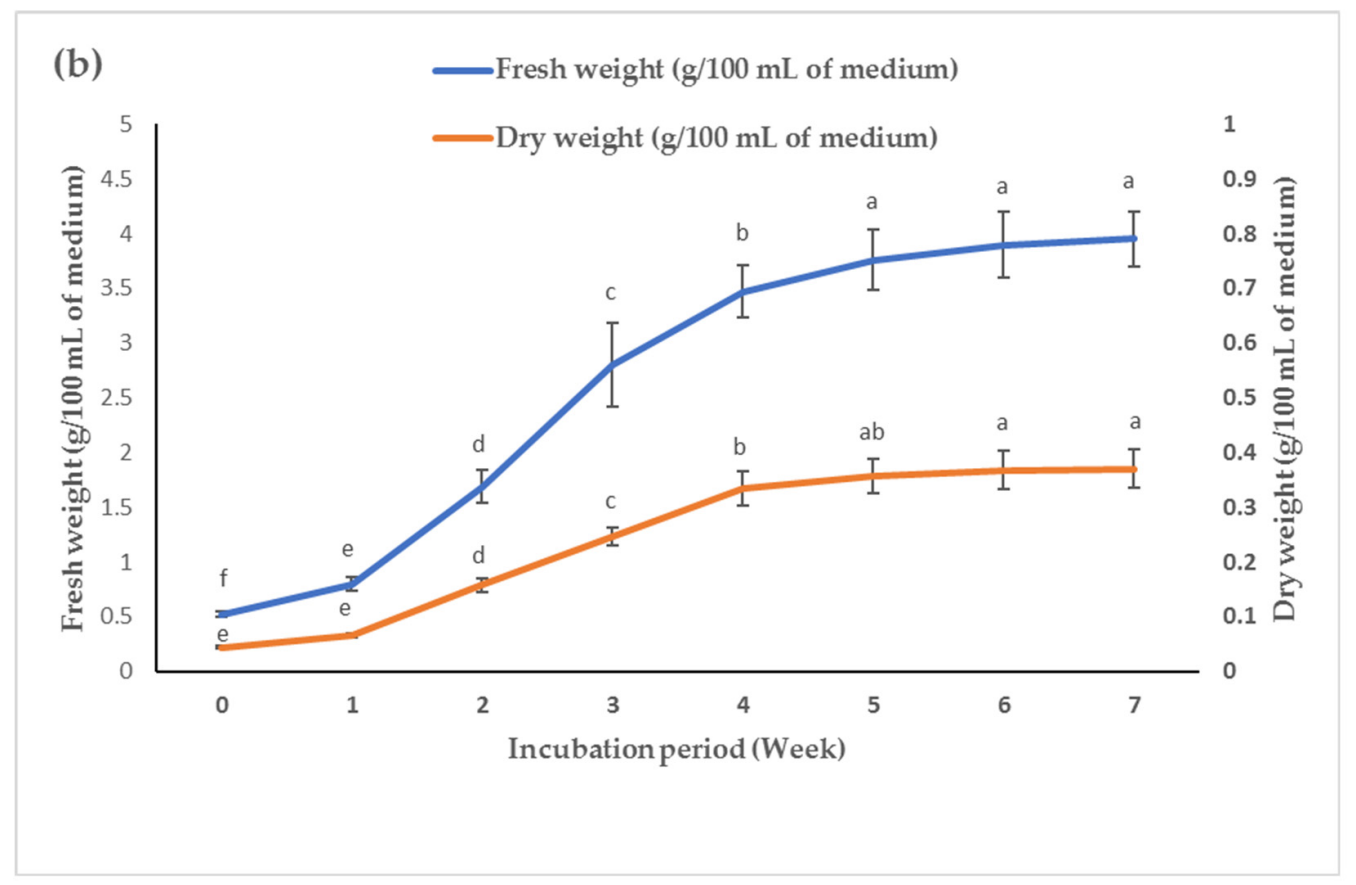

Figure 2. Influence of PGRs on callus induction and growth. (a) Effect of 6-BA (N6-benzyladenine) and NAA (1-Naphthylacetic acid) combination on callus induction; (b) growth of callus culture in MS (Murashige and Skoog) medium with $4 \mu \mathrm{M}$ each of 6-BA and NAA. Different letters in the graph indicate significant differences at $p<0.05$ (DMRT).
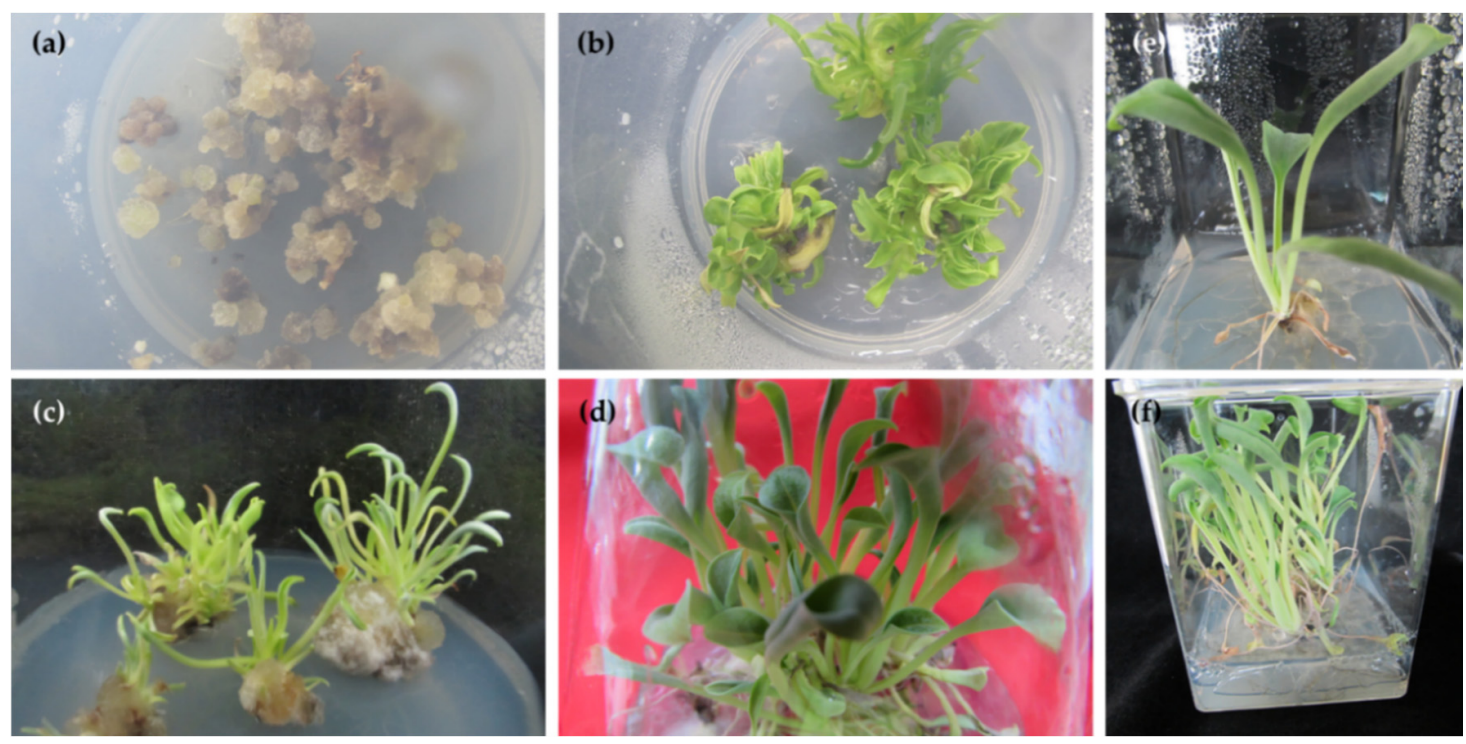

Figure 3. Micropropagation of M. maritima. (a) Callus formed on a culture medium MS (Murashige and Skoog) $+4 \mu \mathrm{M}$ of each 6-BA ( $\mathrm{N}^{6}$-benzyladenine) and NAA (1-Naphthylacetic acid) after 5 weeks; (b) multiple shoots regenerated on a culture medium MS $+2 \mu \mathrm{M}$ 6-BA and $4 \mu \mathrm{M} 6-\mathrm{KN}$ (Kinetin) after 4 weeks; (c) multiple shoots regenerated on culture medium MS $+8 \mu \mathrm{M} 6-\mathrm{KN}$ and $1 \mu \mathrm{M}$ NAA after 4 weeks; (d) shoots elongated on PGR-free MS medium after 5 weeks; tooted shoots on half-strength medium with $2 \mu \mathrm{M}$ Indole-3-butyric acid (e) after 3 weeks and (f) 6 weeks of cultivation.

\subsubsection{Shoot Multiplication}

Nodal explants of M. maritima cultivated on MS without phytohormones (control medium) did not produce axillary shoots and died after 4 weeks of incubation. Shoots developed from explants of M. maritima after 2 weeks of culturing on MS with different 6-BA and 6-KN ( $\mathrm{N}^{6}$-furfuryladenine) 
combinations. Significant $(p<0.05)$ differences were noted in multiple shoot production among the different 6-BA and 6-KN combinations (Table 1). The medium with $2 \mu \mathrm{M} 6-\mathrm{BA}$ and $4 \mu \mathrm{M} 6-\mathrm{KN}$ had the best shoot induction rate $(91.1 \%)$ with a mean of 13.4 shoots (Figure 3b, Table 1$)$. However, the medium containing 6-BA and 6-KN at $8 \mu \mathrm{M}$ was the least effective in promoting the induction of multiple shoots from explants of M. maritima.

Table 1. Influence of 6-BA and 6-KN combinations on shoot proliferation of M. maritima after 4 weeks.

\begin{tabular}{cccc}
\hline 6-BA $(\boldsymbol{\mu M})$ & 6-KN $(\boldsymbol{\mu M})$ & Shoot Induction $\mathbf{( \% )}$ & Number of Shoots \\
\hline 0 & 0 & $0.0 \pm 0.0 \mathrm{i}$ & $0.0 \pm 0.0 \mathrm{f}$ \\
2 & 2 & $54.4 \pm 2.1 \mathrm{~g}$ & $4.6 \pm 0.9 \mathrm{~d}$ \\
4 & 2 & $62.1 \pm 2.9 \mathrm{e}$ & $7.2 \pm 1.2 \mathrm{c}$ \\
8 & 2 & $68.3 \pm 2.5 \mathrm{~d}$ & $6.4 \pm 1.1 \mathrm{c}$ \\
2 & 4 & $91.1 \pm 2.5 \mathrm{a}$ & $13.4 \pm 1.9 \mathrm{a}$ \\
4 & 4 & $83.4 \pm 3.2 \mathrm{~b}$ & $9.8 \pm 1.6 \mathrm{~b}$ \\
8 & 4 & $71.0 \pm 2.9 \mathrm{c}$ & $5.9 \pm 1.4 \mathrm{c}$ \\
2 & 8 & $58.6 \pm 2.4 \mathrm{f}$ & $6.7 \pm 1.2 \mathrm{c}$ \\
4 & 8 & $52.2 \pm 2.6 \mathrm{~g}$ & $4.1 \pm 1.4 \mathrm{de}$ \\
8 & 8 & $39.3 \pm 2.3 \mathrm{~h}$ & $2.9 \pm 0.9 \mathrm{e}$
\end{tabular}

Mean \pm SD with different letters (a-i) are significantly different at $p<0.05$ (DMRT). 6-BA: $\mathrm{N}^{6}$-benzyladenine; 6-KN: Kinetin.

Various 6-BA and NAA combinations were studied for axillary shoot production. Approximately $38.4-72.0 \%$ of nodal explants produced axillary shoots with an average shoot number of 1.7-6.3 after 4 weeks of cultivation on MS with different 6-BA and NAA combinations. The rate of shoot initiation and induced shoot number per node were increased in the medium augmented with $1 \mu \mathrm{M}$ of NAA and all three levels of 6-BA. However, shoot production decreased when the M. maritima nodal segments were cultivated on MS augmented with $2 \mu \mathrm{M}$ of NAA and all three levels of 6-BA. The best combination for axillary shoot production was $8 \mu \mathrm{M}$ 6-BA and $1 \mu \mathrm{M}$ NAA (Table 2). A combination of 6-KN and NAA was also studied for massive axillary shoots regeneration from the nodal segments of M. maritima. Approximately 53.7-80.1\% of nodal explants produced axillary shoots with an average shoot number of 2.3-8.4 after 4 weeks of cultivation on MS with various 6-BA and NAA combinations. Out of the six combined treatments studied, the medium containing $8 \mu \mathrm{M} 6-\mathrm{KN}$ and $1 \mu \mathrm{M}$ NAA induced the highest shoot number (8.4 per node) with an induction rate of $80.1 \%$ (Table 2 ). Calli formed from the base of the nodal segments when they were cultivated on MS augmented with combinations of 6-BA or 6-KN and NAA (Figure 3c). However, the calli induced on all media were unable to differentiate into shoots.

Table 2. Effects of PGRs combinations on shoot multiplication of M. maritima after 4 weeks.

\begin{tabular}{ccccc}
\hline 6-BA $(\boldsymbol{\mu M})$ & 6-KN $(\boldsymbol{\mu M})$ & NAA $(\boldsymbol{\mu M})$ & Shoot Induction $(\%)$ & Number of Shoots \\
\hline 0 & 0 & 0 & $0.0 \pm 0.0 \mathrm{j}$ & $0.0 \pm 0.0 \mathrm{j}$ \\
2 & 0 & 1 & $45.9 \pm 2.6 \mathrm{~h}$ & $3.6 \pm 0.9 \mathrm{ef}$ \\
4 & 0 & 1 & $64.8 \pm 3.3 \mathrm{~cd}$ & $4.7 \pm 0.7 \mathrm{c}$ \\
8 & 0 & 1 & $72.0 \pm 4.0 \mathrm{~b}$ & $6.3 \pm 1.1 \mathrm{~b}$ \\
2 & 0 & 2 & $38.4 \pm 3.9 \mathrm{i}$ & $1.7 \pm 0.5 \mathrm{i}$ \\
4 & 0 & 2 & $41.1 \pm 3.8 \mathrm{i}$ & $2.7 \pm 0.7 \mathrm{gh}$ \\
8 & 0 & 2 & $51.9 \pm 2.8 \mathrm{~g}$ & $3.1 \pm 0.8 \mathrm{efg}$ \\
0 & 2 & 1 & $59.6 \pm 3.6 \mathrm{f}$ & $2.9 \pm 0.8 \mathrm{fgh}$ \\
0 & 4 & 1 & $67.6 \pm 2.7 \mathrm{c}$ & $5.7 \pm 0.7 \mathrm{~b}$ \\
0 & 8 & 1 & $80.1 \pm 3.1 \mathrm{a}$ & $8.4 \pm 0.9 \mathrm{a}$ \\
0 & 2 & 2 & $53.7 \pm 3.4 \mathrm{~g}$ & $2.3 \pm 0.5 \mathrm{hi}$ \\
0 & 4 & 2 & $60.3 \pm 3.6 \mathrm{ef}$ & $3.8 \pm 0.7 \mathrm{de}$ \\
0 & 8 & 2 & $63.0 \pm 3.8 \mathrm{de}$ & $4.4 \pm 0.5 \mathrm{~cd}$ \\
\hline
\end{tabular}

Mean \pm SD with different letters (a-j) are significantly different at $p<0.05$ (DMRT). PGRs: Plant growth regulators; 6-BA: $\mathrm{N}^{6}$-benzyladenine; 6-KN: Kinetin; NAA: 1-Naphthylacetic acid. 


\subsubsection{Shoot Elongation and Root Induction}

Shoots (4 weeks old) obtained from the multiplication medium were elongated on MS medium without any PGR (Figure 3d). The shoots developed adventitious roots after 7 days of cultivation on rooting medium 1/2 MS plus Indole-3-butyric acid (IBA 0-8 $\mu \mathrm{M}$ ). The rooting frequency of $M$. maritima was $56.7 \%$ in the half-strength medium. The rooting rate, number of adventitious roots produced, and mean length varied (Table 3). The inclusion of 1-8 $\mu \mathrm{M}$ IBA in the half-strength medium stimulated adventitious rooting compared to the control (devoid of hormone). The highest number of adventitious roots number (16.2) and their length $\left(7.6 \mathrm{~cm}\right.$ ) were significantly higher on rooting medium $\frac{1}{2} \mathrm{MS}$ with $2 \mu \mathrm{M}$ IBA (Figure 3e,f, Table 3) compared with other treatments. A further increase in the level of IBA declined the number of formed adventitious roots per explant of $M$. maritima and the root growth. However, the rate of root induction was not significantly $(p<0.05)$ different (Table 3$)$.

Table 3. Rooting of M. maritima shoots after 6 weeks of incubation on half strength MS medium with IBA.

\begin{tabular}{cccc}
\hline IBA $(\mu \mathrm{M})$ & Root Induction $(\%)$ & Number of Roots & Root Length $(\mathbf{c m})$ \\
\hline 0 & $56.7 \pm 2.3 \mathrm{c}$ & $3.1 \pm 0.8 \mathrm{~d}$ & $1.6 \pm 0.4 \mathrm{~d}$ \\
1 & $78.8 \pm 3.9 \mathrm{~b}$ & $6.8 \pm 1.1 \mathrm{c}$ & $3.2 \pm 0.5 \mathrm{c}$ \\
2 & $100 \pm 0.0 \mathrm{a}$ & $16.2 \pm 1.9 \mathrm{a}$ & $7.6 \pm 0.6 \mathrm{a}$ \\
4 & $97.5 \pm 3.1 \mathrm{a}$ & $11.3 \pm 1.2 \mathrm{~b}$ & $5.1 \pm 0.6 \mathrm{~b}$ \\
8 & $99.1 \pm 1.1 \mathrm{a}$ & $7.5 \pm 1.3 \mathrm{c}$ & $4.7 \pm 0.7 \mathrm{~b}$ \\
\hline
\end{tabular}

Mean \pm SD with different letters (a-d) are significantly different at $p<0.05$ (DMRT). MS: Murashige and Skoog; IBA: Indole-3-butyric acid.

\subsection{Chemical Composition}

The total amount of phenolic (TAP) and flavonoid (TAF) in the M. maritima tissue extracts was estimated using colorimetric methods, and the data are provided in Table 4 . The shoots $(41.98 \mathrm{mg}$ GAE/g of extract) contained the highest TAP, followed by the seedlings (19.40 mg GAE/g of extract) and calli (11.36 mg GAE/g of extract). Regarding the TAF, we observed the same order: shoots $(1.76 \mathrm{mg}$ $\mathrm{RE} / \mathrm{g}$ of extract $)>$ seedlings $(0.73 \mathrm{mg} \mathrm{RE} / \mathrm{g}$ of extract $)>$ calli $(0.41 \mathrm{mg} \mathrm{RE} / \mathrm{g}$ of extract).

Table 4. TAP and TAF in the M. maritima tissue extracts.

\begin{tabular}{ccc}
\hline Samples & TAP (mg GAE/g of Extract) & TAF (mg RE/g of Extract) \\
\hline Callus & $11.36 \pm 0.16 \mathrm{c}$ & $0.41 \pm 0.04 \mathrm{c}$ \\
Shoots & $41.98 \pm 0.37 \mathrm{a}$ & $1.76 \pm 0.04 \mathrm{a}$ \\
Seedling & $19.40 \pm 0.14 \mathrm{~b}$ & $0.73 \pm 0.04 \mathrm{~b}$ \\
\hline
\end{tabular}

TAP: Total amount of phenolic; TAF: Total amount of flavonoid; GAE: Gallic acid equivalent; RE: Rutin equivalent. Values are expressed as mean \pm SD. Different letters indicate significant differences in the extracts $(p<0.05)$.

Both positive and negative ion electrospray ionization mass spectra were acquired over the mass range 100-1500 Da. Data acquisition was performed in the data-dependent acquisition (DDA) mode. The application of this technique allows the determination of the exact molecular mass, and the fragments were also recoded with high accuracy. The identification of the detected compounds in the calli, shoot, or seedling extracts of M. maritima was based on their fragmentation patterns and chromatographic behaviors (The figures are in Supplementary file: Figures S1-S6). The results showed that, in some cases, the negative mode was more sensitive for the identification of these compounds.

The number of detected compounds and chemical composition in the extracts of the shoots and seedlings of $M$. maritima were similar. In total, 39 compounds were tentatively or unambiguously detected in the shoot extract (Table 5), and 33 compounds were found in the seedling extract (Table 6). Only 18 components were detected in the callus extract (Table 7). 
Table 5. Chemical inventory of shoots of Mertensia maritima

\begin{tabular}{|c|c|c|c|c|c|c|c|c|c|c|}
\hline No. & Name & Formula & Rt & {$[\mathrm{M}+\mathrm{H}]^{+}$} & {$[\mathbf{M}-\mathbf{H}]^{-}$} & Fragment 1 & Fragment 2 & Fragment 3 & Fragment 4 & Fragment 5 \\
\hline 1 & Pantothenic acid & $\mathrm{C}_{9} \mathrm{H}_{17} \mathrm{NO}_{5}$ & 6.09 & 220.11850 & & 202.1075 & 184.0970 & 116.0345 & 90.0554 & 72.0451 \\
\hline 2 & Intermedine or Lycopsamine & $\mathrm{C}_{15} \mathrm{H}_{25} \mathrm{NO}_{5}$ & 7.67 & 300.18110 & & 156.1020 & 138.0915 & 120.0811 & 94.0656 & 82.0657 \\
\hline 3 & Intermedine $\mathrm{N}$-oxide or Lycopsamine $\mathrm{N}$-oxide & $\mathrm{C}_{15} \mathrm{H}_{25} \mathrm{NO}_{6}$ & 12.37 & 316.17602 & & 226.1438 & 172.0967 & 155.0942 & 138.0914 & 94.0655 \\
\hline 4 & Heliotrine or isomer & $\mathrm{C}_{16} \mathrm{H}_{27} \mathrm{NO}_{5}$ & 14.55 & 314.19675 & & 156.1019 & 138.0915 & 120.0810 & 96.0812 & \\
\hline 5 & Caffeic acid & $\mathrm{C}_{9} \mathrm{H}_{8} \mathrm{O}_{4}$ & 15.17 & & 179.03444 & 135.0439 & 107.0485 & & & \\
\hline 6 & Caffeoylshikimic acid & $\mathrm{C}_{16} \mathrm{H}_{16} \mathrm{O}_{8}$ & 18.50 & & 335.07670 & 179.0340 & 161.0233 & 135.0439 & 111.0438 & 93.0330 \\
\hline 7 & Riboflavin & $\mathrm{C}_{17} \mathrm{H}_{20} \mathrm{~N}_{4} \mathrm{O}_{6}$ & 19.07 & 377.14611 & & 359.1364 & 243.0878 & 200.0826 & 172.0868 & 69.0343 \\
\hline 8 & Rosmarinic acid di-O-hexoside isomer 1 & $\mathrm{C}_{30} \mathrm{H}_{36} \mathrm{O}_{18}$ & 21.49 & & 683.18234 & 521.1293 & 359.0996 & 197.0449 & 179.0341 & 135.0439 \\
\hline 9 & Rosmarinic acid di-O-hexoside isomer 2 & $\mathrm{C}_{30} \mathrm{H}_{36} \mathrm{O}_{18}$ & 21.49 & & 683.18234 & 521.1324 & 359.0991 & 197.0448 & 179.0340 & 135.0439 \\
\hline 10 & Apigenin-C-pentoside-O-hexoside & $\mathrm{C}_{26} \mathrm{H}_{28} \mathrm{O}_{14}$ & 21.67 & 565.15574 & & 403.1020 & 385.0918 & 367.0815 & 337.0709 & 283.0602 \\
\hline 11 & Rosmarinic acid $O$-hexoside isomer 1 & $\mathrm{C}_{24} \mathrm{H}_{26} \mathrm{O}_{13}$ & 21.69 & & 521.12952 & 359.0779 & 341.0863 & 179.0340 & 161.0232 & 135.0439 \\
\hline 12 & Rosmarinic acid $O$-hexoside isomer 2 & $\mathrm{C}_{24} \mathrm{H}_{26} \mathrm{O}_{13}$ & 22.43 & & 521.12952 & 359.0774 & 341.0880 & 179.0339 & 161.0232 & 135.0439 \\
\hline 13 & Echimidine or Heliosupine & $\mathrm{C}_{20} \mathrm{H}_{31} \mathrm{NO}_{7}$ & 22.63 & 398.21788 & & 220.1330 & 120.0811 & 83.0498 & & \\
\hline 14 & Echimidine or Heliosupine & $\mathrm{C}_{20} \mathrm{H}_{31} \mathrm{NO}_{7}$ & 23.02 & 398.21788 & & 380.2054 & 220.1331 & 120.0810 & 83.0497 & \\
\hline 15 & Rosmarinic acid $O$-hexoside isomer 3 & $\mathrm{C}_{24} \mathrm{H}_{26} \mathrm{O}_{13}$ & 23.42 & & 521.12952 & 359.0753 & 341.0877 & 179.0340 & 161.0232 & 135.0439 \\
\hline $17^{1}$ & Rutin (Quercetin-3-O-rutinoside) & $\mathrm{C}_{27} \mathrm{H}_{30} \mathrm{O}_{16}$ & 23.53 & & 609.14557 & 300.0277 & 271.0249 & 255.0296 & 178.9977 & 151.0024 \\
\hline 18 & Methyl caffeate & $\mathrm{C}_{10} \mathrm{H}_{10} \mathrm{O}_{4}$ & 24.71 & 195.06574 & & 163.0390 & 145.0285 & 135.0442 & 117.0337 & 107.0495 \\
\hline 19 & Rosmarinic acid (Labiatenic acid) & $\mathrm{C}_{18} \mathrm{H}_{16} \mathrm{O}_{8}$ & 24.73 & & 359.07670 & 197.0448 & 179.0340 & 161.0232 & 135.0438 & 72.9915 \\
\hline 20 & Kaempferol-3-O-rutinoside (Nicotiflorin) & $\mathrm{C}_{27} \mathrm{H}_{30} \mathrm{O}_{15}$ & 25.38 & & 593.15065 & 285.0407 & 284.0329 & 255.0298 & 227.0345 & \\
\hline 21 & Abscisic acid & $\mathrm{C}_{15} \mathrm{H}_{20} \mathrm{O} 4$ & 25.81 & & 263.12834 & 219.1383 & 204.1149 & 201.1278 & 152.0830 & 151.0751 \\
\hline 22 & Ethyl caffeate & $\mathrm{C}_{11} \mathrm{H}_{12} \mathrm{O}_{4}$ & 26.52 & 209.08139 & & 163.0390 & 145.0285 & 135.0443 & 117.0338 & 89.0391 \\
\hline 23 & 3-O-Methylrosmarinic acid & $\mathrm{C}_{19} \mathrm{H}_{18} \mathrm{O}_{8}$ & 26.65 & & 373.09235 & 197.0448 & 179.0340 & 175.0389 & 160.0154 & 135.0439 \\
\hline $24^{1}$ & Quercetin (3,3', 4',5,7-Pentahydroxyflavone) & $\mathrm{C}_{15} \mathrm{H}_{10} \mathrm{O}_{7}$ & 27.56 & & 301.03483 & 178.9979 & 151.0024 & 121.0279 & 107.0123 & \\
\hline 25 & $\begin{array}{l}\text { 3,4-Dihydroxycinnamoyl-2-(3,4-dihydroxyphenyl) } \\
\text { ethenol (cis isomer) }\end{array}$ & $\mathrm{C}_{17} \mathrm{H}_{14} \mathrm{O}_{6}$ & 29.08 & 315.08687 & & 205.0500 & 163.0390 & 145.0285 & 135.0442 & 123.0443 \\
\hline 26 & $\begin{array}{l}\text { 3,4-Dihydroxycinnamoyl-2-(3,4-dihydroxyphenyl) } \\
\text { ethenol (trans isomer) }\end{array}$ & $\mathrm{C}_{17} \mathrm{H}_{14} \mathrm{O}_{6}$ & 30.06 & 315.08687 & & 205.0499 & 163.0390 & 145.0285 & 135.0443 & 123.0443 \\
\hline
\end{tabular}


Table 5. Cont.

\begin{tabular}{|c|c|c|c|c|c|c|c|c|c|c|}
\hline No. & Name & Formula & Rt & {$[\mathrm{M}+\mathrm{H}]^{+}$} & {$\left[\mathrm{M}-\mathrm{H}^{-}\right.$} & Fragment 1 & Fragment 2 & Fragment 3 & Fragment 4 & Fragment 5 \\
\hline 27 & Undecanedioic acid & $\mathrm{C}_{11} \mathrm{H}_{20} \mathrm{O}_{4}$ & 31.36 & & 215.12834 & 197.1177 & 153.1273 & 125.0959 & 57.0332 & \\
\hline 28 & Pentamethoxy(iso)flavone & $\mathrm{C}_{20} \mathrm{H}_{20} \mathrm{O}_{7}$ & 32.92 & 373.12873 & & 358.1035 & 357.1026 & 343.0814 & 327.0867 & 312.0992 \\
\hline 29 & Dodecanedioic acid & $\mathrm{C}_{12} \mathrm{H}_{22} \mathrm{O}_{4}$ & 33.80 & & 229.14399 & 211.1332 & 167.1430 & & & \\
\hline 30 & Dimethoxy(iso)flavone & $\mathrm{C}_{17} \mathrm{H}_{14} \mathrm{O}_{4}$ & 34.14 & 283.09704 & & 268.0730 & 267.0648 & 239.0702 & 225.0550 & \\
\hline 31 & Trimethoxy(iso)flavone isomer 1 & $\mathrm{C}_{18} \mathrm{H}_{16} \mathrm{O}_{5}$ & 34.81 & 313.10760 & & 298.0835 & 297.0754 & 269.0809 & 268.0728 & 255.0655 \\
\hline 32 & Trimethoxy(iso)flavone isomer 2 & $\mathrm{C}_{18} \mathrm{H}_{16} \mathrm{O}_{5}$ & 34.99 & 313.10760 & & 298.0837 & 297.0760 & 269.0807 & 267.0648 & 252.0781 \\
\hline 33 & Tetramethoxy(iso)flavone & $\mathrm{C}_{19} \mathrm{H}_{18} \mathrm{O}_{6}$ & 35.44 & 343.11817 & & 328.0934 & 327.0858 & 314.0780 & 313.0704 & 299.0905 \\
\hline 35 & Dimethoxy-hydroxy(iso)flavone & $\mathrm{C}_{17} \mathrm{H}_{14} \mathrm{O}_{5}$ & 38.94 & 299.09195 & & 284.0678 & 283.0600 & 256.0729 & 255.0648 & \\
\hline 36 & Hexadecanedioic acid & $\mathrm{C}_{16} \mathrm{H}_{30} \mathrm{O}_{4}$ & 40.78 & & 285.20659 & 267.1967 & 223.2062 & & & \\
\hline 37 & Stearidonic acid methyl ester & $\mathrm{C}_{19} \mathrm{H}_{30} \mathrm{O}_{2}$ & 42.16 & 291.23241 & & 259.2058 & 241.1961 & 199.1487 & 135.1170 & 93.0704 \\
\hline 38 & Stearidonic acid ethyl ester & $\mathrm{C}_{20} \mathrm{H}_{32} \mathrm{O}_{2}$ & 43.06 & 305.24806 & & 259.2055 & 241.1955 & 199.1483 & 135.1170 & 93.0703 \\
\hline $39^{1}$ & $\alpha$-Linolenic acid & $\mathrm{C}_{18} \mathrm{H}_{30} \mathrm{O}_{2}$ & 45.13 & & 277.21676 & 259.2064 & 233.2268 & 205.1957 & 59.0122 & \\
\hline
\end{tabular}

${ }^{1}$ Confirmed by standard. Rt: Retention time.

Table 6. Chemical inventory of seedling of Mertensia maritima.

\begin{tabular}{|c|c|c|c|c|c|c|c|c|c|c|}
\hline No. & Name & Formula & $\mathbf{R t}$ & {$[\mathrm{M}+\mathrm{H}]^{+}$} & {$[\mathbf{M}-\mathbf{H}]^{-}$} & Fragment 1 & Fragment 2 & Fragment 3 & Fragment 4 & Fragment 5 \\
\hline 1 & Pantothenic acid & $\mathrm{C}_{9} \mathrm{H}_{17} \mathrm{NO}_{5}$ & 6.09 & 220.11850 & & 202.1075 & 184.0970 & 116.0347 & 90.0555 & 72.0450 \\
\hline 2 & Intermedine or Lycopsamine & $\mathrm{C}_{15} \mathrm{H}_{25} \mathrm{NO}_{5}$ & 7.87 & 300.18110 & & 156.1020 & 138.0915 & 120.0810 & 94.0657 & 82.0657 \\
\hline 3 & Intermedine $\mathrm{N}$-oxide or Lycopsamine $\mathrm{N}$-oxide & $\mathrm{C}_{15} \mathrm{H}_{25} \mathrm{NO}_{6}$ & 12.44 & 316.17602 & & 226.1441 & 172.0968 & 155.0944 & 138.0915 & 94.0656 \\
\hline 4 & Heliotrine or isomer & $\mathrm{C}_{16} \mathrm{H}_{27} \mathrm{NO}_{5}$ & 14.55 & 314.19675 & & 156.1021 & 138.0916 & 120.0806 & 96.0812 & \\
\hline 5 & Caffeic acid & $\mathrm{C}_{9} \mathrm{H}_{8} \mathrm{O}_{4}$ & 15.18 & & 179.03444 & 135.0438 & 107.0489 & & & \\
\hline 6 & Caffeoylshikimic acid & $\mathrm{C}_{16} \mathrm{H}_{16} \mathrm{O}_{8}$ & 18.52 & & 335.07670 & 179.0340 & 161.0232 & 135.0439 & 111.0436 & 93.0330 \\
\hline 7 & Riboflavin & $\mathrm{C}_{17} \mathrm{H}_{20} \mathrm{~N}_{4} \mathrm{O}_{6}$ & 19.07 & 377.14611 & & 359.1354 & 243.0877 & 200.0820 & 172.0870 & 69.0342 \\
\hline 9 & Echimidine or Heliosupine & $\mathrm{C}_{20} \mathrm{H}_{31} \mathrm{NO}_{7}$ & 22.63 & 398.21788 & & 220.1331 & 120.0809 & 83.0498 & & \\
\hline 10 & Echimidine or Heliosupine & $\mathrm{C}_{20} \mathrm{H}_{31} \mathrm{NO}_{7}$ & 22.99 & 398.21788 & & 380.2090 & 220.1333 & 120.0811 & 83.0498 & \\
\hline
\end{tabular}


Table 6. Cont

\begin{tabular}{|c|c|c|c|c|c|c|c|c|c|c|}
\hline No. & Name & Formula & Rt & {$[\mathrm{M}+\mathrm{H}]^{+}$} & {$[\mathbf{M}-\mathbf{H}]^{-}$} & Fragment 1 & Fragment 2 & Fragment 3 & Fragment 4 & Fragment 5 \\
\hline 11 & Rosmarinic acid $O$-hexoside isomer 3 & $\mathrm{C}_{24} \mathrm{H}_{26} \mathrm{O}_{13}$ & 23.46 & & 521.12952 & 359.0769 & 341.0883 & 179.0340 & 161.0232 & 135.0439 \\
\hline $12^{1}$ & Isoquercitrin (Quercetin-3-O-glucoside) & $\mathrm{C}_{21} \mathrm{H}_{20} \mathrm{O}_{12}$ & 23.47 & & 463.08765 & 301.0358 & 300.0277 & 271.0252 & 255.0296 & 151.0024 \\
\hline $13^{1}$ & Rutin (Quercetin-3-O-rutinoside) & $\mathrm{C}_{27} \mathrm{H}_{30} \mathrm{O}_{16}$ & 23.55 & & 609.14557 & 300.0276 & 271.0249 & 255.0297 & 178.9972 & 151.0025 \\
\hline 14 & Methyl caffeate & $\mathrm{C}_{10} \mathrm{H}_{10} \mathrm{O}_{4}$ & 24.76 & 195.06574 & & 163.0390 & 145.0285 & 135.0442 & 117.0338 & 107.0496 \\
\hline 15 & Rosmarinic acid (Labiatenic acid) & $\mathrm{C}_{18} \mathrm{H}_{16} \mathrm{O}_{8}$ & 24.80 & & 359.07670 & 197.0448 & 179.0339 & 161.0231 & 135.0438 & 72.9915 \\
\hline 16 & Kaempferol-3-O-rutinoside (Nicotiflorin) & $\mathrm{C}_{27} \mathrm{H}_{30} \mathrm{O}_{15}$ & 25.40 & & 593.15065 & 285.0405 & 284.0328 & 255.0296 & 227.0346 & \\
\hline 17 & Abscisic acid & $\mathrm{C}_{15} \mathrm{H}_{20} \mathrm{O}_{4}$ & 25.83 & & 263.12834 & 219.1382 & 204.1143 & 201.1274 & 152.0833 & 151.0750 \\
\hline 19 & 3-O-Methylrosmarinic acid & $\mathrm{C}_{19} \mathrm{H}_{18} \mathrm{O}_{8}$ & 26.65 & & 373.09235 & 197.0448 & 179.0339 & 175.0389 & 160.0153 & 135.0439 \\
\hline $20^{1}$ & Quercetin (3,3', 4',5,7-Pentahydroxyflavone) & $\mathrm{C}_{15} \mathrm{H}_{10} \mathrm{O}_{7}$ & 27.58 & & 301.03483 & 178.9981 & 151.0025 & 121.0280 & 107.0123 & \\
\hline 21 & $\begin{array}{l}\text { 3,4-Dihydroxycinnamoyl-2-(3,4-dihydroxyphenyl) } \\
\text { ethenol (cis isomer) }\end{array}$ & $\mathrm{C}_{17} \mathrm{H}_{14} \mathrm{O}_{6}$ & 29.07 & 315.08687 & & 205.0495 & 163.0391 & 145.0287 & 135.0444 & 123.0442 \\
\hline 22 & $\begin{array}{l}\text { 3,4-Dihydroxycinnamoyl-2-(3,4-dihydroxyphenyl) } \\
\text { ethenol (trans isomer) }\end{array}$ & $\mathrm{C}_{17} \mathrm{H}_{14} \mathrm{O}_{6}$ & 30.07 & 315.08687 & & 205.0498 & 163.0391 & 145.0286 & 135.0443 & 123.0443 \\
\hline 23 & Undecanedioic acid & $\mathrm{C}_{11} \mathrm{H}_{20} \mathrm{O}_{4}$ & 31.37 & & 215.12834 & 197.1176 & 153.1272 & 125.0956 & 57.0331 & \\
\hline 24 & Pentamethoxy(iso)flavone & $\mathrm{C}_{20} \mathrm{H}_{20} \mathrm{O}_{7}$ & 32.92 & 373.12873 & & 358.1046 & 357.1057 & 343.0808 & 327.0869 & 312.0989 \\
\hline 26 & Dimethoxy(iso)flavone & $\mathrm{C}_{17} \mathrm{H}_{14} \mathrm{O}_{4}$ & 34.14 & 283.09704 & & 268.0731 & 267.0650 & 239.0706 & 225.0552 & \\
\hline 27 & Trimethoxy(iso)flavone isomer 1 & $\mathrm{C}_{18} \mathrm{H}_{16} \mathrm{O}_{5}$ & 34.81 & 313.10760 & & 298.0840 & 297.0751 & 269.0808 & 268.0738 & 255.0655 \\
\hline 28 & Trimethoxy(iso)flavone isomer 2 & $\mathrm{C}_{18} \mathrm{H}_{16} \mathrm{O}_{5}$ & 35.00 & 313.10760 & & 298.0837 & 297.0762 & 269.0817 & 267.0648 & 252.0775 \\
\hline 29 & Tetramethoxy(iso)flavone & $\mathrm{C}_{19} \mathrm{H}_{18} \mathrm{O}_{6}$ & 35.44 & 343.11817 & & 328.0948 & 327.0864 & 314.0786 & 313.0704 & 299.0929 \\
\hline 30 & Tetradecanedioic acid & $\mathrm{C}_{14} \mathrm{H}_{26} \mathrm{O}_{4}$ & 37.73 & & 257.17529 & 239.1647 & 195.1747 & & & \\
\hline 31 & Hexadecanedioic acid & $\mathrm{C}_{16} \mathrm{H}_{30} \mathrm{O}_{4}$ & 40.77 & & 285.20659 & 267.1966 & 223.2061 & & & \\
\hline 32 & Stearidonic acid methyl ester & $\mathrm{C}_{19} \mathrm{H}_{30} \mathrm{O}_{2}$ & 42.15 & 291.23241 & & 259.2060 & 241.1949 & 199.1483 & 135.1170 & 93.0703 \\
\hline $33^{1}$ & $\alpha$-Linolenic acid & $\mathrm{C}_{18} \mathrm{H}_{30} \mathrm{O}_{2}$ & 45.13 & & 277.21676 & 259.2064 & 233.2272 & 205.1977 & 59.0123 & \\
\hline
\end{tabular}

${ }^{1}$ Confirmed by standard. Rt: Retention time. 
Table 7. Chemical inventory of callus of Mertensia maritima.

\begin{tabular}{|c|c|c|c|c|c|c|c|c|c|c|}
\hline No. & Name & Formula & $\mathbf{R t}$ & {$[\mathrm{M}+\mathrm{H}]^{+}$} & {$[\mathrm{M}-\mathrm{H}]^{-}$} & Fragment 1 & Fragment 2 & Fragment 3 & Fragment 4 & Fragment 5 \\
\hline 1 & Intermedine $\mathrm{N}$-oxide or Lycopsamine $\mathrm{N}$-oxide & $\mathrm{C}_{15} \mathrm{H}_{25} \mathrm{NO}_{6}$ & 12.47 & 316.17602 & & 226.1437 & 172.0968 & 155.0940 & 138.0915 & 94.0657 \\
\hline 2 & Vanillic acid & $\mathrm{C}_{8} \mathrm{H}_{8} \mathrm{O}_{4}$ & 14.42 & & 167.03444 & 152.0103 & 123.0437 & 108.0202 & & \\
\hline 3 & Caffeic acid & $\mathrm{C}_{9} \mathrm{H}_{8} \mathrm{O}_{4}$ & 15.19 & & 179.03444 & 135.0438 & 107.0489 & & & \\
\hline 4 & Riboflavin & $\mathrm{C}_{17} \mathrm{H}_{20} \mathrm{~N}_{4} \mathrm{O}_{6}$ & 19.06 & 377.14611 & & 359.1311 & 243.0876 & 200.0819 & 172.0867 & 69.0341 \\
\hline 5 & Ferulic acid & $\mathrm{C}_{10} \mathrm{H}_{10} \mathrm{O}_{4}$ & 19.91 & & 193.05009 & 178.0261 & 149.0596 & 137.0232 & 134.0361 & 121.0279 \\
\hline 6 & Isoferulic acid & $\mathrm{C}_{10} \mathrm{H}_{10} \mathrm{O}_{4}$ & 20.93 & & 193.05009 & 178.0263 & 149.0596 & 137.0228 & 134.0360 & \\
\hline $7^{1}$ & Rutin (Quercetin-3-O-rutinoside) & $\mathrm{C}_{27} \mathrm{H}_{30} \mathrm{O}_{16}$ & 23.55 & & 609.14557 & 300.0279 & 271.0255 & 255.0288 & 178.9974 & 151.0022 \\
\hline 8 & Unidentified alkaloid & $\mathrm{C}_{16} \mathrm{H}_{15} \mathrm{NO}_{5}$ & 24.39 & 302.10285 & & 284.0915 & 141.0699 & 134.0449 & 116.0345 & 88.0398 \\
\hline 9 & Rosmarinic acid (Labiatenic acid) & $\mathrm{C}_{18} \mathrm{H}_{16} \mathrm{O}_{8}$ & 24.78 & & 359.07670 & 197.0449 & 179.0341 & 161.0232 & 135.0439 & 72.9915 \\
\hline 10 & Methoxy-methylcoumarin isomer 1 & $\mathrm{C}_{11} \mathrm{H}_{10} \mathrm{O}_{3}$ & 25.75 & 191.07082 & & 176.0468 & 148.0519 & 135.0805 & 131.0491 & 105.0702 \\
\hline 11 & Camphanic acid or isomer & $\mathrm{C}_{10} \mathrm{H}_{14} \mathrm{O}_{4}$ & 27.41 & & 197.08139 & 153.0909 & 85.0279 & & & \\
\hline 12 & Methoxy-methylcoumarin isomer 2 & $\mathrm{C}_{11} \mathrm{H}_{10} \mathrm{O}_{3}$ & 28.09 & 191.07082 & & 176.0468 & 148.0519 & 135.0806 & 131.0492 & 105.0703 \\
\hline 13 & Undecanedioic acid & $\mathrm{C}_{11} \mathrm{H}_{20} \mathrm{O}_{4}$ & 31.35 & & 215.12834 & 197.1177 & 153.1273 & 125.0959 & 57.0332 & \\
\hline 14 & Dodecanedioic acid & $\mathrm{C}_{12} \mathrm{H}_{22} \mathrm{O}_{4}$ & 33.81 & & 229.14399 & 211.1332 & 167.1429 & & & \\
\hline 15 & Dimethoxy(iso)flavone & $\mathrm{C}_{17} \mathrm{H}_{14} \mathrm{O}_{4}$ & 34,14 & 283.09704 & & 268.0729 & 267.0650 & 239.0701 & 225.0539 & \\
\hline 17 & Tetradecanedioic acid & $\mathrm{C}_{14} \mathrm{H}_{26} \mathrm{O}_{4}$ & 37.73 & & 257.17529 & 239.1650 & 195.1748 & & & \\
\hline 18 & Hexadecanedioic acid & $\mathrm{C}_{16} \mathrm{H}_{30} \mathrm{O}_{4}$ & 40.78 & & 285.20659 & 267.1966 & 223.2061 & & & \\
\hline
\end{tabular}

${ }^{1}$ Confirmed by standard. Rt: Retention time. 
Further, pantothenic; undecanedioic; dodecanedioic; tetradecanedioic; hexadecanedioic; stearidonic acid and their derivatives; abscisic acid; intermedine or lycopsamine and their $\mathrm{N}$-oxide; heliotrine; caffeic acid and its derivatives; rosmarinic acid and its di-O-hexoside isomers; 3-O-methylrosmarinic acid; apigenin- $\mathrm{C}$-pentoside-O-hexoside; echimidine or heliosupine; quercetin and isoquercitine; 3,4-dihydrocinnamic acid derivatives; and di-, tri-, tetra-, pentamethoxy(iso)flavone isomers were assigned to the extracts.

In some cases, two or three isomers of compounds could be tentatively identified in the extracts. For example, two isomers of rosmarinic acid di-O-hexoside were identified in the shoot extract. A typical extracted ion chromatogram of these compounds at m/z 683.1823 and Figures 4-6 shows the MS2 spectra (negative ion mode).

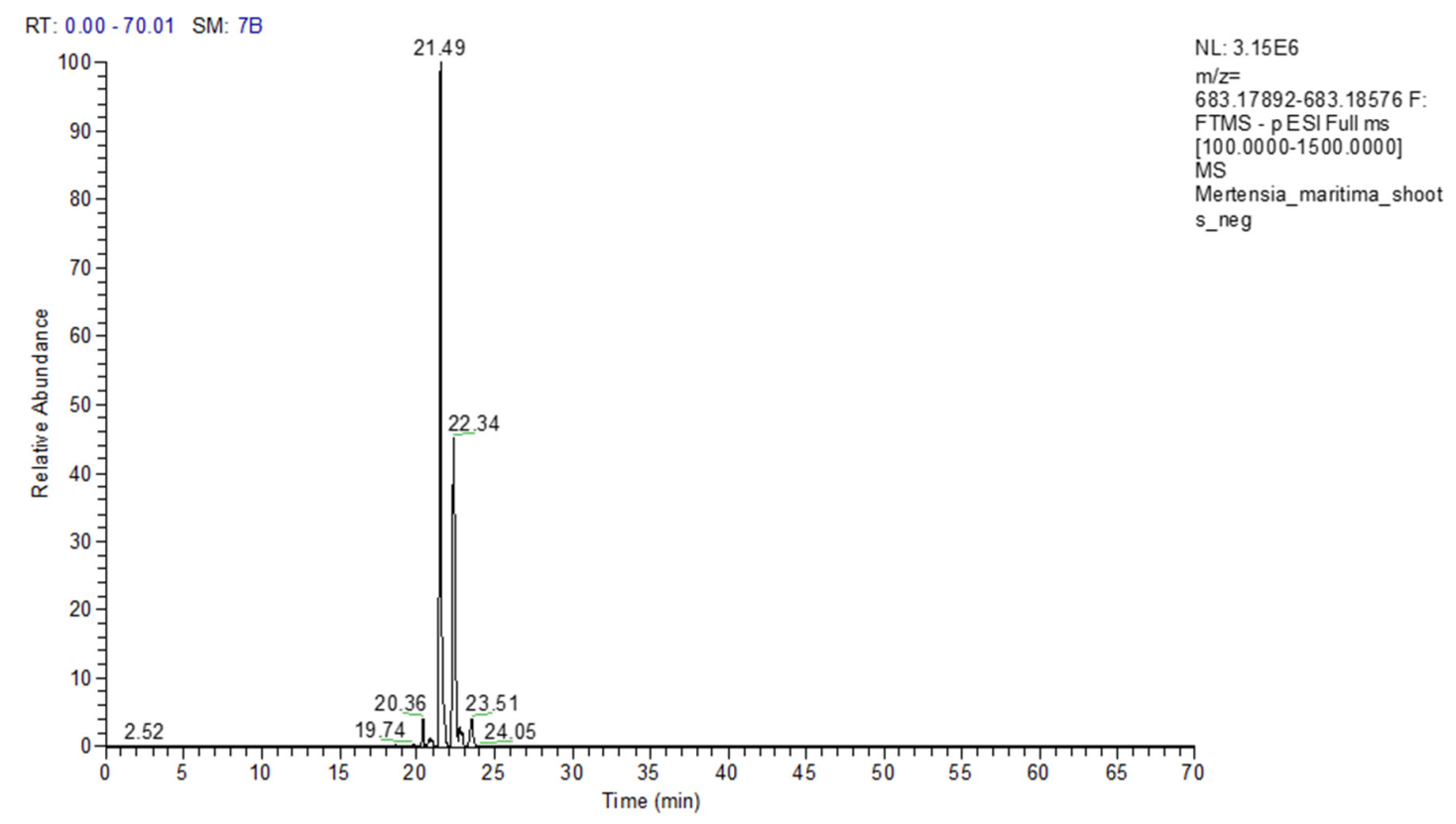

Figure 4. Extracted Ion Chromatogram (XIC) of rosmarinic acid di-O-hexoside isomers at $\mathrm{m} / \mathrm{z} 683.1823$ $\left([\mathrm{M}-\mathrm{H}]^{-}\right)$in the shoots extract.

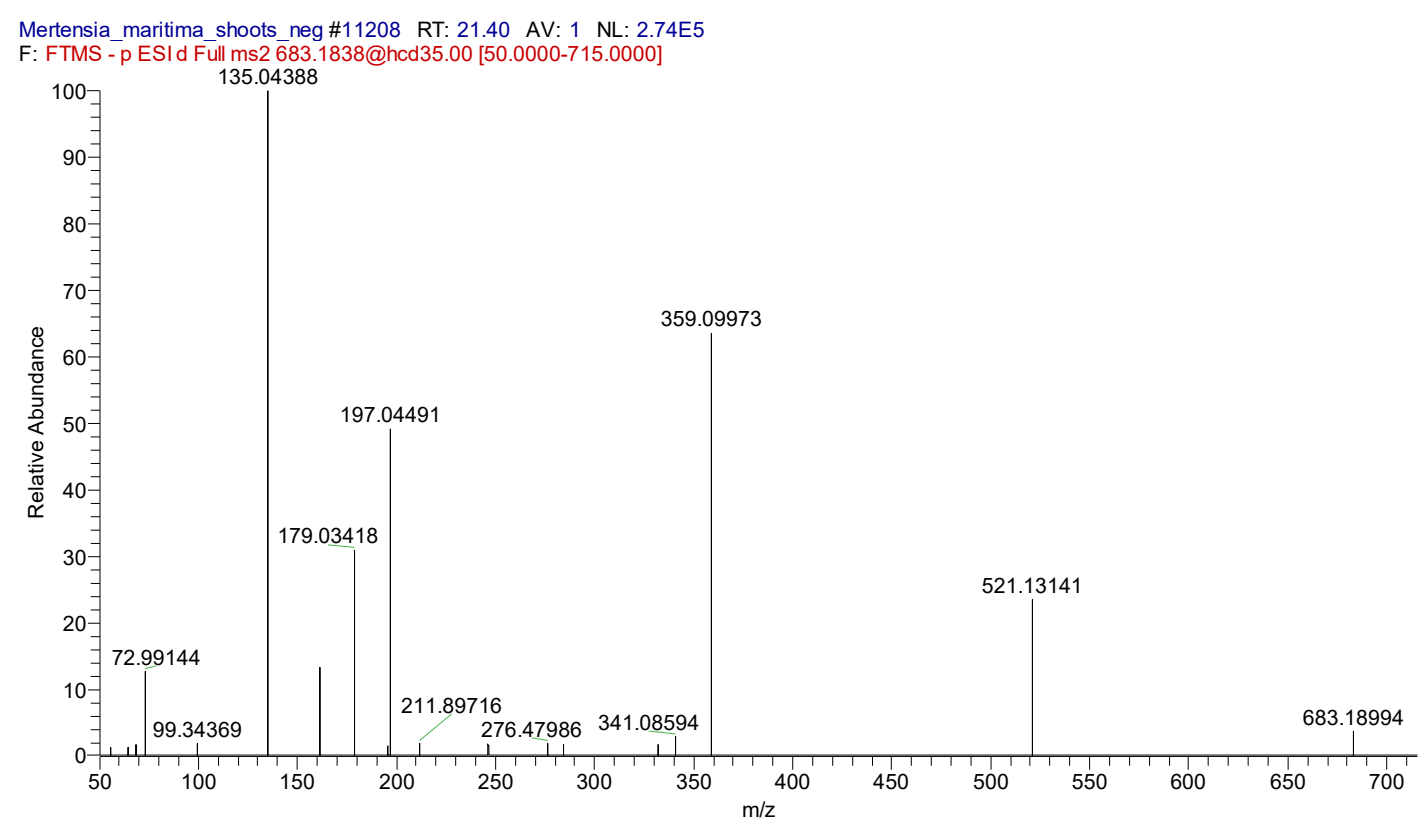

Figure 5. MS2 spectrum of rosmarinic acid di-O-hexoside isomer 1 at $21.49 \mathrm{~min}$ (ESI-). 


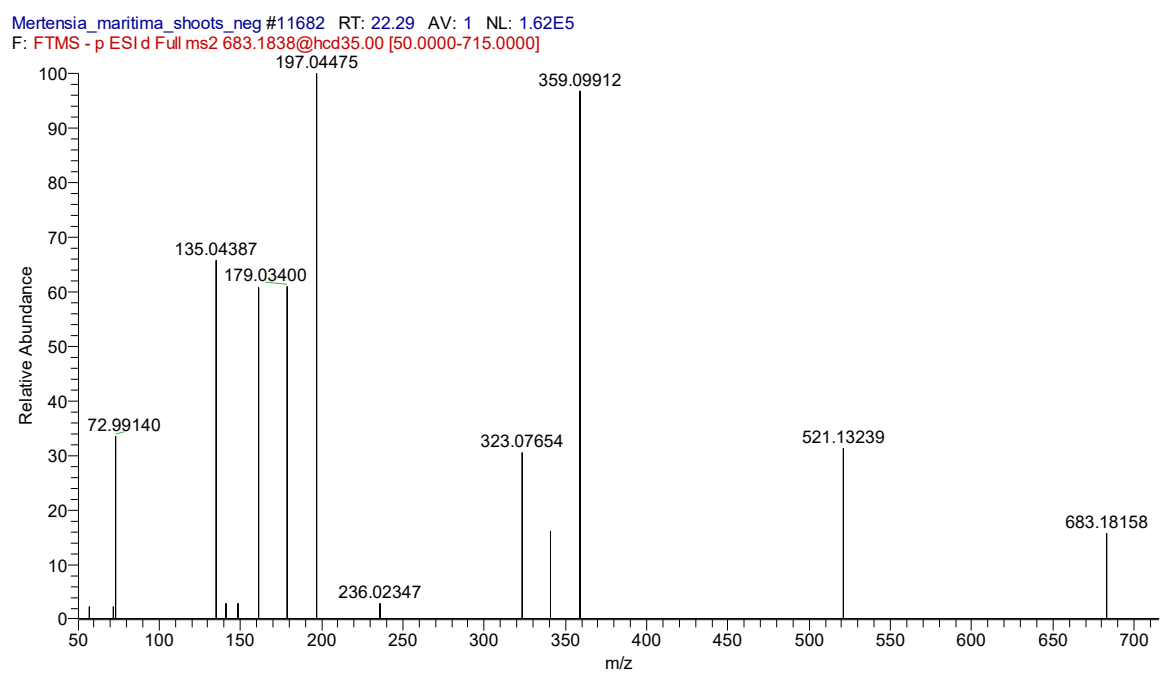

Figure 6. MS2 spectrum of rosmarinic acid di-O-hexoside isomer 2 at $22.34 \mathrm{~min}$ (ESI-).

\subsection{Biological Activities}

The antioxidant activities of M. maritima calli, shoot, or seedling extracts were evaluated using different test systems, and the results are provided in Table 8 . The best antioxidant capacity was obtained in the shoots, followed by the seedlings and calli in the radical scavenging ABTS (2,2-azino-bis (3-ethylbenzothiazoline-6-sulphonic acid) and DPPH (2,2-diphenyl-1-picrylhydrazyl), reducing power FRAP (ferric reducing antioxidant power) and CUPRAC (cupric reducing antioxidant capacity), and phosphomolybdenum (PBD) assays. However, the order was seedlings $>$ calli $>$ shoots with regards to the MCA (metal chelating ability).

Table 8. Antioxidant properties of the extracts $(\mathrm{IC} 50(\mathrm{mg} / \mathrm{mL}))$.

\begin{tabular}{ccccccc}
\hline Samples & DPPH & ABTS & CUPRAC & FRAP & PBD & Chelating \\
\hline Callus & $>3$ & $>3$ & $2.91 \pm 0.01 \mathrm{~d}$ & $1.77 \pm 0.01 \mathrm{~d}$ & $>3$ & $1.94 \pm 0.15 \mathrm{c}$ \\
Shoots & $0.57 \pm 0.01 \mathrm{~b}$ & $0.78 \pm 0.01 \mathrm{~b}$ & $0.55 \pm 0.01 \mathrm{~b}$ & $0.35 \pm 0.01 \mathrm{~b}$ & $1.60 \pm 0.05 \mathrm{~b}$ & $>3$ \\
Seedling & $1.18 \pm 0.01 \mathrm{c}$ & $1.63 \pm 0.03 \mathrm{c}$ & $1.33 \pm 0.01 \mathrm{c}$ & $0.81 \pm 0.01 \mathrm{c}$ & $2.91 \pm 0.07 \mathrm{c}$ & $1.23 \pm 0.20 \mathrm{~b}$ \\
Trolox & $0.06 \pm 0.01 \mathrm{a}$ & $0.09 \pm 0.01 \mathrm{a}$ & $0.11 \pm 0.01 \mathrm{a}$ & $0.04 \pm 0.01 \mathrm{a}$ & $0.52 \pm 0.02 \mathrm{a}$ & nt \\
EDTA & nt & nt & nt & nt & nt & $0.02 \pm 0.001 \mathrm{a}$ \\
\hline
\end{tabular}

DPPH: 2,2-Diphenyl-1-picrylhydrazyl; ABTS: 2,2-Azino-bis(3-ethylbenzothiazoline-6-sulphonic acid); CUPRAC: Cupric reducing antioxidant capacity; FRAP: Ferric reducing antioxidant power; PBD: Phosphomolybdenum; nt: no tested. Values are expressed as mean \pm SD. Different letters indicate significant differences in the extracts $(p<0.05)$.

The enzyme inhibitory effects of M. maritima calli, shoot, or seedling extracts were investigated against $\mathrm{AChE}$ (acetylcholinesterase) and $\mathrm{BChE}$ (butylcholinestrase), tyrosinase, and amylase. Values are presented in Table 9 . The strongest AChE inhibition properties were obtained by the calli, followed by seedlings and shoots. However, the tested samples were ranked as seedlings $>$ shoots $>$ calli in the BChE inhibition assay. Regarding the antityrosinase inhibition ability, the strongest ability was detected in the seedlings $\left(\mathrm{IC}_{50}: 0.74 \mathrm{mg} / \mathrm{mL}\right)$, followed by the calli $\left(\mathrm{IC}_{50}: 0.80 \mathrm{mg} / \mathrm{mL}\right)$ and shoots $\left(\mathrm{IC}_{50}: 0.87 \mathrm{mg} / \mathrm{mL}\right)$. The anti-amylase activities of the samples were almost the same $\left(\mathrm{IC}_{50}: 1.40-147 \mathrm{mg} / \mathrm{mL}\right)$.

Table 9. Enzyme inhibitory properties of the extracts (IC50 (mg/mL)).

\begin{tabular}{ccccc}
\hline Samples & AChE & BChE & Tyrosinase & Amylase \\
\hline Callus & $0.78 \pm 0.01 \mathrm{~b}$ & $1.92 \pm 0.17 \mathrm{~d}$ & $0.80 \pm 0.01 \mathrm{c}$ & $1.40 \pm 0.08 \mathrm{~b}$ \\
Shoots & $1.21 \pm 0.07 \mathrm{~d}$ & $1.66 \pm 0.08 \mathrm{bc}$ & $0.87 \pm 0.01 \mathrm{~d}$ & $1.45 \pm 0.02 \mathrm{~b}$ \\
Seedling & $0.89 \pm 0.02 \mathrm{c}$ & $1.35 \pm 0.16 \mathrm{~b}$ & $0.74 \pm 0.01 \mathrm{~b}$ & $1.47 \pm 0.05 \mathrm{~b}$ \\
Galantamine & $0.003 \pm 0.001 \mathrm{a}$ & $0.007 \pm 0.002 \mathrm{a}$ & $\mathrm{nt}$ & $\mathrm{nt}$ \\
Kojic acid & nt & nt & $0.08 \pm 0.001 \mathrm{a}$ & nt \\
Acarbose & nt & nt & nt & $0.68 \pm 0.01 \mathrm{a}$ \\
\hline
\end{tabular}

AChE: Acetylcholinesterase; BChE: Butylcholinestrase; $n t:$ no tested. Values are expressed as mean \pm SD. Different letters indicate significant differences in the extracts $(p<0.05)$. 


\section{Discussion}

Callus induction and axillary shoot multiplication are significant in vitro technologies for the rapid commercial production of plantlets and bioactive metabolites. Leaf explants from M. maritima initiated calli only on PGR (6-BA and NAA) supplemented MS medium. A combination of PGRs such as cytokinin and auxin are generally used to induce callus initiation in M. maritima [5] and several other Boraginaceae members such as Alkanna orientalis (L.) Boiss. and A. sieheana Rech. f. [8], Arnebia euchroma (Royle) Jonst. [9], Arnebia hispidissima (Lehm.) A. DC. [10], Echium italicum L. [11], Eritrichium sericeum (Lehm.) A. DC. [12], Onosma bulbotrichum [13], and Onosma sericeum Willd [14]. In this study, the highest callus proliferation was attained after 5 weeks of cultivation under a 16-h photoperiod on MS medium augmented with $4 \mu \mathrm{M}$ of each 6-BA and NAA. Fedoreyev et al. [5] also obtained maximum callus growth in M. maritima on $\mathrm{W}_{\mathrm{B} / \mathrm{A}}$ medium containing $2.2 \mu \mathrm{M}$ 6-BA and $10.8 \mu \mathrm{M}$ NAA after 30 days of cultivation in the dark. However, there was a considerable difference in the optimal levels of 6-BA and NAA. The differences in the optimal concentration of 6-BA and NAA required for the best callus growth may be due to culture conditions, callus type, and growth media.

Nodal explants of $M$. maritima failed to regenerate in MS medium lacking PGR. This is consistent with an earlier study of $M$. maritima [6]. Similar results have been reported for Boraginaceae members such as Hackelia venusta (Piper) H.St.John [15] and Trichodesma indicum (Linn) R. Br. [16]. Axillary shoot multiplication can be achieved by supplementing the growth media with optimal levels of PGRs. Cytokinin is a class of PGR that promotes axillary shoot multiplication by antagonizing apical shoot dominance. Nodal segments of M. maritima cultivated on medium with 6-BA and 6-KN produced axillary shoots (Table 1). Cytokinins (for shoot production) and their concentrations were chosen based on our previous study [6]. The explants cultivated on medium with $2 \mu \mathrm{M}$ 6-BA and $4 \mu \mathrm{M}$ 6-KN developed more shoots (13.4) than those on media containing the other five 6-BA and 6-KN combinations (Table 1). The combinations of two cytokinins (6-BA and 6-KN) were found to be effective in the shoot regeneration of Boraginaceae members [10,17]. Kumar and Rao [17] reported that Heliotropium indicum L. axillary buds inoculated on medium with $4.7 \mu \mathrm{M} 6-\mathrm{KN}$ and $2.2 \mu \mathrm{M}$ 6-BA developed 11.8 shoots.

Several studies have shown that media with cytokinin and auxin enhance shoot proliferation in numerous members of the Boraginaceae family, including M. maritima [6,16-19]. The ratio of cytokinin and auxin is crucial for the production of multiple shoots. In general, high cytokinin/auxin ratio promotes shoot proliferation in many plants [20]. In this study, supplementing MS with a high level of 6-BA or 6-KN $(8 \mu \mathrm{M})$ and low level of NAA $(1 \mu \mathrm{M})$ yielded the maximum number of shoots. However, the incorporation of a high concentration of NAA $(2 \mu \mathrm{M})$ in media containing 6-BA or 6-KN inhibited shoot proliferation. Similar results have been described for A. hispidissima [18], H. indicum [17], and T. indicum [16]. The MS added with $8 \mu \mathrm{M} 6-\mathrm{KN}$ and $1 \mu \mathrm{M}$ NAA produced the maximum (8.4) number of shoots (Table 2). This number was lower than that reported for oyster plant [6]. Maximal shoot production was 17.7 shoots per node for M. maritima and was stimulated by $4 \mu \mathrm{M}$ TDZ and $1 \mu \mathrm{M}$ NAA [6].

The incorporation of IBA in $\frac{1}{2}$ MS enhanced the rooting response of the explants (Table 3). IBA was chosen for in vitro rooting because it has been reported to be beneficial for adventitious root induction in M. maritima [6] and other Boraginaceae members [10,16-18]. However, the rooting response of shoots under in vitro conditions varied with the IBA concentration. The optimal level of IBA required for the rooting of micro shoots depends on the rooting medium strength, the composition of shoot production medium, plant species, and genotype [20]. In this study, the best rooting was attained with $2 \mu \mathrm{M}$ IBA in M. maritima. However, the rooting of M. maritima was the most effective in half-strength medium with $4 \mu \mathrm{M}$ IBA [6]. MS with $9.8 \mu \mathrm{M}$ IBA exhibited the best rooting in A. hispidissima [18], half-strength medium with $0.49 \mu \mathrm{M}$ IBA showed the best rooting in $H$. indicum [17], and MS with $2.46 \mu \mathrm{M}$ IBA displayed the best rooting in T. indicum [16].

Phenolics are unique compounds with significant biological properties, including antioxidant, anti-microbial, and anti-cancer activities [21]. In this context, the determination of the TAP in plant 
extracts is the first step; for this purpose, a colorimetric method was developed by Folin and Ciocalteu [22]. The TAP in the shoots was $216.4 \%$ and $369.5 \%$ higher than in seedlings and calli, respectively. The TAP in $M$. maritima shoots extract was also larger (41.98 $\mathrm{mg}$ GAE/g of extract) than in calli (9.20 GAE/g of extract), in vivo leaves (16.06 GAE/g of extract), stems (14.55 GAE/g of extract), inflorescences (21.70 GAE/g of extract) and roots (3.17 GAE/g of extract) of Heliotropium indicum [23], flowers (18.43 GAE/g of extract) and roots (13.11 GAE/g of extract) of Cynoglossum creticum [24], and aerial parts (32.7 GAE/g of extract) [25] and roots (11.45 GAE/g of extract) of Symphytum anatolicum [26]. The TAP in the shoots was $241.1 \%$ and $429.3 \%$ higher than in seedlings and calli, respectively. However, TAP in M. maritima shoot tissues was lower (1.76 mg RE/g of extract) compared to in vivo leaves (4.39 RE/g of extract) and flowers (21.77 RE/g of extract) of C. creticum [24], aerial parts (20.9 RE/g of extract) of Cynoglottis barrelieri [25], leaves (3.32 QE/g of extract), stems (3.23 QE/g of extract) and inflorescences (4.90 QE/g of extract) of $H$. indicum [23], and aerial parts (13.3 RE/g of extract) [25] and roots (2.74 RE/g of extract) of S. anatolicum [26]. Folin and Ciocalteu method, one of the most popular, is simple and requires inexpensive reagents. However, in recent times, there have been some concerns regarding the use of colorimetric methods, and some authors reported that these assays do not accurately reflect the levels of phytochemicals in extracts. This fact is related to the reduction of the Folin-Ciocalteu reagent by not only phenolics but also non-phenolic compounds [27]. In this sense, at least one chromatographic technique (HPLC, LC-MS, or LC-MS/MS) is important for determining accurate levels of bioactive compounds. Hence, we determined the chemical profiles of M. maritima extracts using the UHPLC-MS/MS technique.

The oyster plant is eaten by the Iñupiat of Alaska. It is cultivated as an edible plant in southwestern France and Northern Scotland [4] for their fragrant leaves. Thus, knowledge of its chemical composition is necessary. Pyrrolizidine alkaloids are one of the main bioactive compounds of Boraginaceae members [28]. For the first time, seven pyrrolizidine alkaloids, such as echimidine, heliosupine, heliotrine, intermedine or lycopsamine, and their N-oxides were identified in $M$. maritima extracts by UHPLC-MS/MS (Tables 5-7). The occurrence of these compounds was also disclosed in numerous members of the Boraginaceae family, including Mertensia species [3,28,29]. Four and six fatty acids were identified in callus and tissue extracts of M. maritima by UHPLC-MS/MS (Table 5-7). Among the fatty acids detected, $\alpha$-linolenic acid and stearidonic acid were reported in M. maritima [6]. In this study, undecanedioic, dodecanedioic, tetradecanedioic, and hexadecanedioic acids were identified in M. maritima, for the first time. Of the phenolic compounds detected, only rosmarinic acid was reported in the callus extract of M. maritima [5]. Whereas other phenolic compounds were found in members of the Boraginaceae [30-34].

In the last few decades, the terms "antioxidant" and "oxidative stress" have become popular terms in the scientific community [35]. This fact could be explained by the role of oxidative stress in the progression of chronic and degenerative diseases [36]. In light of this information, we determined the antioxidant profiles of $M$. maritima extracts using different chemical methods. Except for the metal chelation assay, the best antioxidant properties were obtained in the shoot, followed by the seedling and callus. The order is in line with the levels of TAP and TAF. These findings showed that phenolics were the main contributors of the antioxidant capacities of the M. maritima extract. This fact also was confirmed by correlation analysis, and the results are given in Figure 7. In addition, this approach was also confirmed by several authors who reported a linear relationship between total phenolics and antioxidant properties [37-39]. In addition, individual compounds, including caffeic acid [40], rosmarinic acid [41], and rutin [42], have been reported as significant antioxidants. The contents of these compounds are relatively high in members of the Boraginaceae family, including M. maritima [5,30,32-34]. Phenolic compounds with one or more hydroxyl groups are effective hydrogen or electron donors. Regarding the metal chelating ability, the contradictory results could be explained by the presence of non-phenolic chelators in M. maritima shoot extracts, including polysaccharides, peptides, or vitamin C [43]. 


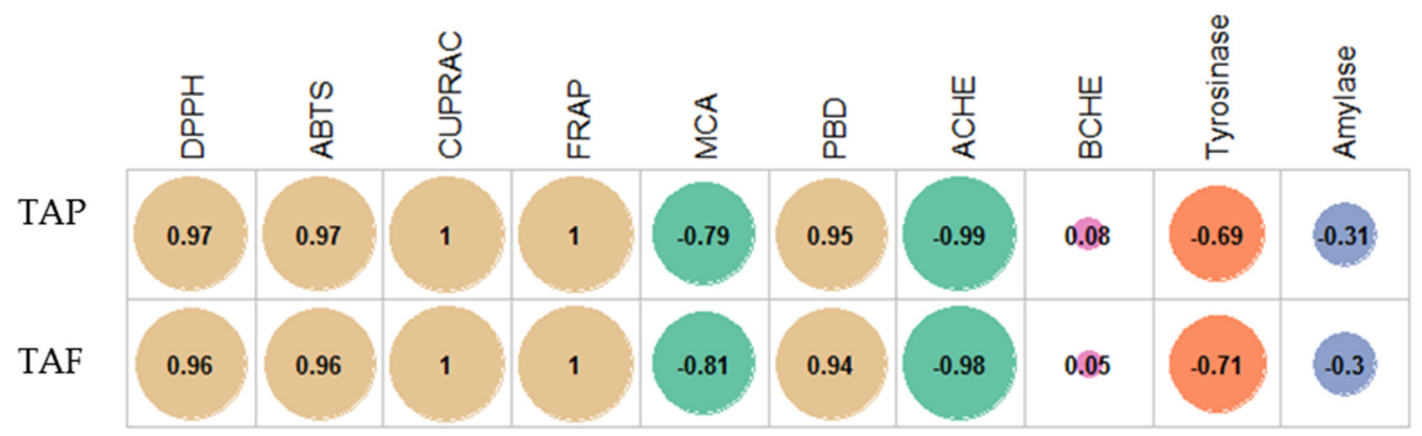

Figure 7. Pearson correlation between TAP, TAF and biological activities $(p<0.05)$. TAP: Total amount of phenolic; TAF: Total amount of flavonoid; DPPH: 2,2-Diphenyl-1-picrylhydrazyl; ABTS: 2,2-Azinobis(3-ethylbenzothiazoline-6-sulphonic acid); CUPRAC: Cupric reducing antioxidant capacity; FRAP: Ferric reducing antioxidant power; MCA: Metal chelating ability; PBD: Phosphomolybdenum; AChE: Acetylcholinesterase; BChE: Butylcholinestrase.

According to WHO reports, diseases such as heart disease, stroke, chronic pulmonary disease, Alzheimer's disease, and diabetes mellitus are the biggest killers worldwide [44]. The inhibition of cholinesterase increases the level of acetylcholine, which could enhance the memory capacity in patients with Alzheimer's [45]. Similarly, the inhibition of carbohydrate-hydrolyzing enzymes can retard the increase in blood glucose levels in patients with diabetes [46]. Hence, several compounds are synthetically produced as enzyme inhibitors in the pharmaceutical industry. However, several studies have reported that synthetic compounds have unpleasant side effects $[47,48]$. Thus, enzyme inhibitors from natural sources are needed to replace these synthetic ones. In recent investigations, several researchers reported enzyme inhibition properties of several Boraginaceae members such as, Alkanna sfikasiana [49], Cynoglossum creticum [24], Cynoglottis barrelieri [25], Echium confusum [50], Onosma aucheriana, Onosma sieheana, Onosma frutescens, Onosma stenoloba, and Onosma sericea [51,52] Symphytum anatolicum $[25,26]$. In the present study, the enzyme inhibitory effects of M. maritima extracts were investigated using different enzymes. Among the three M. martima tissue extracts studied, calli extracts exhibited ideal AChE (IC50: $0.74 \mathrm{mg} / \mathrm{mL}$ ) inhibition, seedlings extracts exhibited ideal BChE (IC50: $0.74 \mathrm{mg} / \mathrm{mL}$ ) inhibition and tyrosinase (IC50: $0.74 \mathrm{mg} / \mathrm{mL}$ ) inhibition, while all three extracts exhibited similar amylase (IC50: $1.40-1.47 \mathrm{mg} / \mathrm{mL}$ ) inhibition activity (Table 9). The IC50 values attained from tyrosinase and amylase inhibition assays were lower compared to several other Boraginaceae members [51,52]. We observed different results for each enzyme inhibition ability. The observed enzyme inhibitory effects could be explained by the chemical profiles of the extracts. Some compounds in the chemical profiles, including caffeic acid [53,54], rosmarinic acid [55,56], and rutin $[57,58]$ have been reported as significant enzyme inhibitor agents in previous studies. To our knowledge, the present study is the first report on the enzyme inhibitory effects of M. maritima extracts, and these findings could provide valuable contributions to the scientific community.

\section{Materials and Methods}

\subsection{In Vitro Propagation}

\subsubsection{Surface Disinfection, Media, and Culture Conditions}

Leaf and node explants of M. maritima used in callus and shoot regeneration studies were harvested from plants cultivated in a greenhouse. The shoots were cautiously rinsed with water for $15 \mathrm{~min}$ and then surface decontaminated in ethanol $(70 \% v / v)$ for $90 \mathrm{~s}$; rinsed twice in sterilized distilled water and sodium hypochlorite solution ( $2 \% v / v)$ with 2-3 drops of nonionic detergent (Tween 20) for 10 min; washed three to five times in sterilized distilled water and ethanol $(70 \% v / v)$ for $90 \mathrm{~s}$; and rinsed twice in sterilized distilled water [6]. The cultivation media consisted of MS [59] minerals, vitamins, PGRs, sugar (30 g/L sucrose), and solidifying agent ( $8 \mathrm{~g} / \mathrm{L}$ plant agar). The $\mathrm{pH}$ of all cultivation media was 
adjusted to $5.75 \pm 0.25$ before being autoclaved for $20 \mathrm{~min}$ at $121{ }^{\circ} \mathrm{C}$. Leaf (callus), callus (proliferation), node (multiple shoot), micro shoot (elongation), and well-developed shoot (rooting) explant cultures were incubated for $5,7,4,5$, and 6 weeks, respectively, at $22-24{ }^{\circ} \mathrm{C}$ under a 16 -h photoperiod $\left(55 \pm 5 \mu \mathrm{mol} \mathrm{m}^{-2} \mathrm{~s}^{-1}\right)$.

\subsubsection{Callus Induction}

Leaf explants (5-10 $\mathrm{mm}$ ) were prepared from surface-disinfected M. maritima shoots placed on medium with 0,2 , or $4 \mu \mathrm{M}$ 6-BA in combination with $0,2,4$, or $8 \mu \mathrm{M}$ of NAA for callus formation. To study the growth of $M$. maritima callus, approximately $50 \mathrm{mg}$ of callus was inoculated on a growth medium containing $4 \mu \mathrm{M}$ of each 6-BA and NAA. Each callus initiation or callus growth treatment consisted of 15 or 25 leaf or callus explants with three replicates. Callusing percentages and fresh and dry weights of calluses were recorded.

\subsubsection{Shoot Multiplication}

Node explants (approximately $5 \mathrm{~mm}$ ) were prepared from surface-disinfected M. maritima shoots placed on medium with 6-BA and 6-KN (Table 1), 6-BA and NAA, or 6-KN and NAA combinations (Table 2) for multiple shoot induction. Each multiple shoot production treatment consisted of 25 nodes with three replicates. Shooting percentages and shoot numbers were recorded.

\subsubsection{Shoot Elongation and Root Induction}

For elongation of M. maritima shoots, in vitro-induced shoot masses obtained from medium with $2 \mu \mathrm{M}$ 6-BA and $4 \mu \mathrm{M}$ 6-KN were transferred to PGRs-free growth medium. After 5 weeks, well-developed shoots ( $\geq 2 \mathrm{~cm}$ in height) were cultured on medium $\frac{1}{2}$ MS with 0-8 $\mu \mathrm{M}$ IBA for rooting. Each root induction treatment consisted of 25 shoots with three replicates. Rooting percentages, number, and length of roots were recorded.

\subsection{Phytochemical Analysis}

\subsubsection{Extract Preparation}

Calli (obtained from the medium with $4 \mu \mathrm{M}$ each of 6-BA and NAA), leaves (obtained from shoots developed in PGR-free medium), and seedlings (obtained from the greenhouse) were collected after 5 weeks of cultivation; they were lyophilized and then powdered. The samples (50 mg) were extracted with methanol ( $80 \%)$ using an Ultraturrax at $6000 \mathrm{~g}$ for $20 \mathrm{~min}$. After, filtration solvents were removed using a rotary evaporator and kept at plus $4{ }^{\circ} \mathrm{C}$ until further use.

\subsubsection{Determination of TAP and TAF}

TAP in calli, shoot, or seedling extracts of M. maritima was assessed using the Folin-Ciocalteu method, as adapted by Slinkard and Singleton [60] and calculated as gallic acid equivalent (GAE). TAF in calli, shoot, or seedling extracts of M. maritima was estimated using the aluminum chloride $\left(\mathrm{AlCl}_{3}\right)$ method, as adapted by Zengin et al. [61] and was calculated as RE. All assays were performed in three analytical replications.

\subsubsection{Identification and Quantification of Phytochemicals}

The qualitative analysis of phytochemicals in calli, shoot, or seedling extracts of M. maritima was carried out using an UHPLC instrument (Dionex Ultimate 3000 RS, Thermo Scientific, MA, 01001 USA) connected to a mass spectrometer (Q Exactive Orbitrap, Thermo Scientific, USA). Thermo Accucore C18 column $(100 \mathrm{~mm}$ length $\times 2.1 \mathrm{~mm}$ column I.D., $2.6 \mu \mathrm{m})$ was used for chromatographic separation [62]. Analytical details are presented in the supplementary material. 


\subsection{Biological Activities}

\subsubsection{Antioxidant Assay}

ABTS, DPPH, FRAP, CUPRAC, MCA, and PBD assays were conducted to estimate the antioxidant ability of calli, shoot, or seedling extracts of M. maritima and standards (Trolox and EDTA) [63]. All assays were performed in three analytical replications.

\subsubsection{Enzyme Inhibitory Assay}

Amylase-, AChE-, BChE-, and tyrosinase-inhibitory activity of calli, shoot, or seedling extracts of M. maritima was determined according to Uysal et al. [63]. All assays were performed in three analytical replications.

\subsection{Statistical Analysis}

Data obtained such as callusing, shooting, rooting, TAP, TAF, and antioxidant and enzyme inhibition were analyzed in SAS version 9.1. Analysis of variance and Duncan (at $5 \%$ level) were used to test the influence and significance of treatments, respectively. For correlation analysis (Pearson coefficient), R software v. 3.5.1 was used.

\section{Conclusions}

An improved in vitro micropropagation method for M. maritima was established. This in vitro callus and shoot proliferation method will be useful for the extraction of bioactive metabolites from M. maritima. The synthesis of bioactive metabolites in M. maritima cell and shoot cultures is affected by chemical factors. Thus, further research on the optimization of growth media, culture environment, and elicitation are needed to maximize bioactive metabolite production in M. maritima in vitro cultures.

Supplementary Materials: The following are available online at http://www.mdpi.com/2223-7747/9/11/1551/s1, UHPLC methods and Figures S1-S6.

Author Contributions: Conceptualization, K.S., D.H.K. and I.S.; methodology, I.S., G.A., G.Z., Z.C., J.J.; formal analysis, K.S., K.R.R.; investigation, I.S., G.A., Z.C.; data curation, O.N.L.; writing-original draft preparation, K.S., G.A., G.Z., Z.C., J.J., I.S.; writing-review and editing, K.R.R., G.A., G.Z., I.S.; funding acquisition, I.S. All authors have read and agreed to the published version of the manuscript.

Funding: This research was funded by Konkuk University.

Acknowledgments: This article was supported by the KU Research Professor Program of Konkuk University.

Conflicts of Interest: The authors declare no conflict of interest.

\section{References}

1. Nazaire, M.; Wang, X.Q.; Hufford, L. Geographic origins and patterns of radiation of Mertensia (Boraginaceae). Am. J. Bot. 2014, 101, 104-118. [CrossRef]

2. Gracie, C. Spring Wildflowers of the Northeast; Princeton University Press: Princeton, NJ, USA, 2012; pp. $222-227$.

3. Li, Y.; Stermitz, F.R. Pyrrolizidine alkaloids from Mertensia species of Colorado. J. Nat. Prod. 1988, 51, 1289-1290. [CrossRef]

4. Delort, E.; Jaquier, A.; Chapuis, C.; Rubin, M.; Starken-mann, C.J. Volatile composition of oyster leaf (Mertensia maritima (L.) Gray). J. Agric. Food Chem. 2012, 60, 11681-11690. [CrossRef] [PubMed]

5. Fedoreyev, S.A.; Inyushkina, Y.V.; Bulgakov, V.P.; Veselova, M.V.; Tchernoded, G.K.; Gerasimenko, A.V.; Zhuravlev, Y.N. Production of allantoin, rabdosiin and rosmarinic acid in callus cultures of the seacostal plant Mertensia maritima (Boraginaceae). Plant. Cell Tissue Organ. Cult. 2012, 110, 183-188. [CrossRef]

6. Park, H.Y.; Kim, D.H.; Saini, R.K.; Gopal, J.; Keum, Y.S.; Sivanesan, I. Micropropagation and quantification of bioactive compounds in Mertensia maritima (L.) Gray. Int. J. Mol. Sci. 2019, 20, 2141. [CrossRef] [PubMed]

7. Alton, S.; FitzGerald, R. Mertensia maritima Boraginaceae. Curtis's Bot. Mag. 2009, 26, 96-110. [CrossRef]

8. Yaman, C.; Uranbey, S.; Ahmed, H.; Özcan, S.; Tugay, O.; Başalma, D. Callus induction and regeneration of Alkanna orientalis var. Orientalis and A. sieheana. Bangladesh J. Bot. 2019, 48, 633-640. [CrossRef] 
9. Damianakos, H.; Kretschmer, N.; Syklowska-Baranek, K.; Pietrosiuk, A.; Bauer, R.; Chinou, I. Antimicrobial and cytotoxic isohexenylnaphthazarins from Arnebia euchroma (Royle) Jonst. (Boraginaceae) callus and cell suspension culture. Molecules 2012, 17, 14310-14322. [CrossRef]

10. Phulwaria, M.; Shekhawat, N.S. An efficient in vitro shoot regeneration from immature inflorescence and ex vitro rooting of Arnebia hispidissima (Lehm). DC.-A red dye (Alkannin) yielding plant. Physiol. Mol. Biol. Plants 2013, 19, 435-441. [CrossRef]

11. Zare, K.; Khosrowshahli, M.; Nazemiyeh, H.; Movafeghi, A.; Motallebi Azar, A.; Omidi, Y. Callus culture of Echium italicum L. towards production of a shikonin derivative. Nat. Prod. Res. 2011, 25, 1480-1487. [CrossRef]

12. Fedoreyev, S.A.; Veselova, M.V.; Krivoschekova, O.E.; Mischenko, N.P.; Denisenko, V.A.; Dmitrenok, P.S.; Glazunov, V.P.; Bulgakov, V.P.; Tchernoded, G.K.; Zhuravlev, Y.N. Caffeic acid metabolites from Eritrichium sericeum cell cultures. Planta Med. 2005, 71, 446-451. [CrossRef] [PubMed]

13. Bagheri, F.; Tahvilian, R.; Karimi, N.; Chalabi, M.; Azam, M. Shikonin production by callus culture of Onosma bulbotrichom as active pharmaceutical ingredient. Iran J. Pharm. Res. 2018, 17, 495-504. [PubMed]

14. Gharehmatrossian, S.; Popov, Y.; Ghorbanli, M.; Safaeian, S.; Iranbakhsh, A. Phytochemical and morphological evidences for shikonin production by plant cell cultures of Onosma sericeum Willd. Braz. Arch. Biol. Technol. 2016, 59, e16160235. [CrossRef]

15. Edson, J.L.; Leege-Brusven, A.D.; Everett, R.L.; Wenny, D.L. Minimizing growth regulators in shoot cultures of an endangered plant, Hackelia venusta (Boraginaceae). In Vitro Cell. Dev. Biol. Plant 1996, 32, 267-271. [CrossRef]

16. Mahesh, A.; Jeyachandran, R. Influence of plant growth regulators on micropropagation and in vitro flowering of Trichodesma indicum (Linn) R. Br. Plant. Biosyst. 2013, 147, 493-499. [CrossRef]

17. Kumar, M.S.; Rao, M.V. In vitro micropropagation of Heliotropium indicum L.-An ayurvedic herb. Indian J. Biotechnol. 2007, 6, 245-249.

18. Pal, M.; Chaudhury, A. High frequency direct plant regeneration, micropropagation and shikonin induction in Arnebia hispidissima. J. Crop. Sci. Biotech. 2010, 13, 13-19. [CrossRef]

19. Lameira, O.A.; Pinto, J.E.B.P. In vitro propagation of Cordia verbenacea (Boraginaceae). Rev. Bras. Plant Med. Botucatu. 2006, 8, 102-104.

20. Park, H.Y.; Kim, D.H.; Sivanesan, I. Micropropagation of Ajuga species: A mini review. Biotechnol. Lett. 2017, 39, 1291-1298. [CrossRef]

21. Wang, Z.; Li, S.; Ge, S.; Lin, S. Review of distribution, extraction methods, and health benefits of bound phenolics in food plants. J. Agric. Food Chem. 2020, 68, 3330-3343. [CrossRef]

22. Folin, O.; Ciocalteu, V. On tyrosine and tryptophane determinations in proteins. J. Biol. Chem. 1927, 73, 627-650.

23. Kumar, M.S.; Chaudhury, S.; Balachandran, S. In vitro callus culture of Heliotropium indicum Linn. for assessment of total phenolic and flavonoid content and antioxidant activity. Appl. Biochem. Biotechnol. 2014, 174, 2897-2909. [CrossRef] [PubMed]

24. Menghini, L.; Ferrante, C.; Zengin, G.; Mahomoodally, M.F.; Leporini, L.; Locatelli, M.; Cacciagrano, F.; Recinella, L.; Chiavaroli, A.; Leone, S.; et al. Multiple pharmacological approaches on hydroalcoholic extracts from different parts of Cynoglossum creticum Mill. (Boraginaceae). Plant Biosyst. 2019, 153, 633-639. [CrossRef]

25. Varvouni, E.-F.; Zengin, G.; Graikou, K.; Ganos, C.; Mroczek, T.; Chinou, I. Phytochemical analysis and biological evaluation of the aerial parts from Symphytum anatolicum Boiss. and Cynoglottis barrelieri (All.) Vural \& Kit Tan (Boraginaceae). Biochem. Syst. Ecol. 2020, 92, 104128.

26. Sarikurkcu, C.; Ozer, M.S.; Tlili, N. LC-ESI-MS/MS characterization of phytochemical and enzyme inhibitory effects of different solvent extract of Symphytum anatolicum. Ind. Crop. Prod. 2019, 140, 111666. [CrossRef]

27. Sánchez-Rangel, J.C.; Benavides, J.; Heredia, J.B.; Cisneros-Zevallos, L.; Jacobo-Velázquez, D.A. The Folin-Ciocalteu assay revisited: Improvement of its specificity for total phenolic content determination. Anal. Methods 2013, 5, 5990-5999. [CrossRef]

28. El-Shazly, A.; Wink, M. Diversity of pyrrolizidine alkaloids in the Boraginaceae structures, distribution, and biological properties. Diversity 2014, 6, 188-282. [CrossRef]

29. Schramm, S.; Köhler, N.; Rozhon, W. Pyrrolizidine Alkaloids: Biosynthesis, Biological Activities and Occurrence in Crop Plants. Molecules 2019, 24, 498. [CrossRef] 
30. Zemmouri, H.; Ammar, S.; Boumendjel, A.; Messarah, M.; El Feki, A.; Bouaziz, M. Chemical composition and antioxidant activity of Borago officinalis L. leaf extract growing in Algeria. Arab. J. Chem. 2019, 12, 1954-1963. [CrossRef]

31. Dresler, S.; Szymczak, G.; Wójcik, M. Comparison of some secondary metabolite content in the seventeen species of the Boraginaceae family. Pharm. Biol. 2017, 55, 691-695. [CrossRef]

32. Li, L.; Li, M.-H.; Xu, L.-J.; Guo, N.; Wu-Lan, T.-N.; Shi, R.-B.; Peng, Y.; Xiao, P.-G. Distribution of seven polyphenols in several medicinal plants of Boraginaceae in China. J. Med. Plants Res. 2010, 4, 1216-1221.

33. Bai, X.R.; Zhang, N.; Ren, K.; Xu, J.P.; Li, Z.Y.; Zhang, C.H.; Li, M.H. Chemical constituents from Stenosolenium saxatile (Pall.) turcz. (Boraginaceae) Biochem. Systemat. Ecol. 2017, 74, 30-32. [CrossRef]

34. Trifan, A.; Skalicka-Woźniak, K.; Granica, S.; Czerwińska, M.E.; Kruk, A.; Marcourt, L.; Wolfender, J.-L.; Wolfram, E.; Esslinger, N.; Grubelnik, A.; et al. Symphytum officinale L.: Liquid-liquid chromatography isolation of caffeic acid oligomers and evaluation of their influence on pro-inflammatory cytokine release in LPS-stimulated neutrophils. J. Ethnopharmacol. 2020, 262, 113169. [CrossRef]

35. Yeung, A.W.K.; Tzvetkov, N.T.; El-Tawil, O.S.; Bungǎu, S.G.; Abdel-Daim, M.M.; Atanasov, A.G. Antioxidants: Scientific literature landscape analysis. Oxidative Med. Cell. Longev. 2019, 2019. [CrossRef]

36. Bjørklund, G.; Chirumbolo, S. Role of oxidative stress and antioxidants in daily nutrition and human health. Nutrition 2017, 33, 311-321. [CrossRef]

37. Ghafoor, K.; Al Juhaimi, F.; Özcan, M.M.; Uslu, N.; Babiker, E.E.; Ahmed, I.A.M. Total phenolics, total carotenoids, individual phenolics and antioxidant activity of ginger (Zingiber officinale) rhizome as affected by drying methods. LWT 2020, 126, 109354. [CrossRef]

38. Muhammad, H.; Qasim, M.; Ikram, A.; Versiani, M.A.; Tahiri, I.A.; Yasmeen, K.; Abbasi, M.W.; Azeem, M.; Ali, S.T.; Gul, B. Antioxidant and antimicrobial activities of Ixora coccinea root and quantification of phenolic compounds using HPLC. S. Afr. J. Bot. 2020, 135, 71-79. [CrossRef]

39. Vidal-Gutiérrez, M.; Robles-Zepeda, R.E.; Vilegas, W.; Gonzalez-Aguilar, G.A.; Torres-Moreno, H.; López-Romero, J.C. Phenolic composition and antioxidant activity of Bursera microphylla A. Gray. Ind. Crop. Prod. 2020, 152, 112412. [CrossRef]

40. Espíndola, K.M.M.; Ferreira, R.G.; Narvaez, L.E.M.; Silva Rosario, A.C.R.; da Silva, A.H.M.; Silva, A.G.B.; Vieira, A.P.O.; Monteiro, M.C. Chemical and pharmacological aspects of caffeic acid and its activity in hepatocarcinoma. Front. Oncol. 2019, 9, 541. [CrossRef]

41. Nadeem, M.; Imran, M.; Aslam Gondal, T.; Imran, A.; Shahbaz, M.; Muhammad Amir, R.; Wasim Sajid, M.; Batool Qaisrani, T.; Atif, M.; Hussain, G.; et al. Therapeutic potential of rosmarinic acid: A comprehensive review. Appl. Sci. 2019, 9, 3139. [CrossRef]

42. Gullón, B.; Lú-Chau, T.A.; Moreira, M.T.; Lema, J.M.; Eibes, G. Rutin: A review on extraction, identification and purification methods, biological activities and approaches to enhance its bioavailability. Trends Food Sci. Technol. 2017, 67, 220-235. [CrossRef]

43. Sarikurkcu, C.; Zengin, G. Polyphenol profile and biological activity comparisons of different parts of Astragalus macrocephalus subsp. finitimus from Turkey. Biology 2020, 9, 231. [CrossRef]

44. WHO. 2020. Available online: https://www.who.int/news-room/fact-sheets/detail/the-top-10-causes-of-death (accessed on 12 September 2020).

45. Mishra, P.; Kumar, A.; Panda, G. Anti-cholinesterase hybrids as multi-target-directed ligands against Alzheimer's disease (1998-2018). Bioorgan. Med. Chem. 2019, 27, 895-930. [CrossRef]

46. Sun, L.; Wang, Y.; Miao, M. Inhibition of $\alpha$-amylase by polyphenolic compounds: Substrate digestion, binding interactions and nutritional intervention. Trends Food Sci. Technol. 2020, 104, 190-207. [CrossRef]

47. Dorababu, A. Critical evaluation of current Alzheimer's drug discovery (2018-19) \& futuristic Alzheimer drug model approach. Bioorgan. Chem. 2019, 93, 103299.

48. Ni, M.; Hu, X.; Gong, D.; Zhang, G. Inhibitory mechanism of vitexin on $\alpha$-glucosidase and its synergy with acarbose. Food Hydrocoll. 2020, 105, 105824. [CrossRef]

49. Tufa, T.; Damianakos, H.; Zengin, G.; Graikou, K.; Chinou, I. Antioxidant and enzyme inhibitory activities of disodium rabdosiin isolated from Alkanna sfikasiana Tan, Vold and Strid. S. Afr. J. Bot. 2019, 120, 157-162. [CrossRef]

50. Benamar, H.; Tomassini, L.; Venditti, A.; Marouf, A.; Bennaceur, M.; Serafini, M.; Nicoletti, M. Acetylcholinesterase inhibitory activity of pyrrolizidine alkaloids from Echium confusum Coincy. Nat. Prod. Res. 2017, 31, 1277-1285. [CrossRef] 
51. Sarikurkcu, C.; Sahinler, S.S.; Tepe, B. Onosma aucheriana, O. frutescens, and O. sericea: Phytochemical profiling and biological activity. Ind. Crop. Prod. 2020, 154, 112633. [CrossRef]

52. Sarikurkcu, C.; Sahinler, S.S.; Husunet, M.T.; Istifli, E.S.; Tepe, B. Two endemic Onosma species (O. sieheana and O. stenoloba): A comparative study including docking data on biological activity and phenolic composition. Ind. Crop. Prod. 2020, 154, 112656. [CrossRef]

53. Oboh, G.; Agunloye, O.M.; Adefegha, S.A.; Akinyemi, A.J.; Ademiluyi, A.O. Caffeic and chlorogenic acids inhibit key enzymes linked to type 2 diabetes (in vitro): A comparative study. J. Basic Clin. Physiol. Pharmacol. 2015, 26, 165-170. [CrossRef]

54. Agunloye, O.M.; Oboh, G. Modulatory effect of caffeic acid on cholinesterases inhibitory properties of donepezil. J. Complement. Integr. Med. 2017, 15, 20170016. [CrossRef] [PubMed]

55. Gülçin, İ.; Scozzafava, A.; Supuran, C.T.; Koksal, Z.; Turkan, F.; Çetinkaya, S.; Bingöl, Z.; Huyut, Z.; Alwasel, S.H. Rosmarinic acid inhibits some metabolic enzymes including glutathione S-transferase, lactoperoxidase, acetylcholinesterase, butyrylcholinesterase, and carbonic anhydrase isoenzymes. J. Enzyme Inhib. Med. Chem. 2016, 31, 1698-1702. [CrossRef] [PubMed]

56. Mccue, P.; Shetty, K. Inhibitory effects of rosmarinic acid extracts on porcine pancreatic amylase in vitro. Asia Pac. J. Clin. Nutr. 2004, 13, 101-106. [PubMed]

57. Oboh, G.; Ademosun, A.O.; Ayeni, P.O.; Omojokun, O.S.; Bello, F. Comparative effect of quercetin and rutin on $\alpha$-amylase, $\alpha$-glucosidase, and some pro-oxidant-induced lipid peroxidation in rat pancreas. Comp. Clin. Pathol. 2015, 24, 1103-1110. [CrossRef]

58. Ademosun, A.O.; Oboh, G.; Bello, F.; Ayeni, P.O. Antioxidative properties and effect of quercetin and its glycosylated form (Rutin) on acetylcholinesterase and butyrylcholinesterase Activities. J. Evid. Based Complement. Altern. Med. 2016, 21, Np11-Np17.

59. Murashige, T.; Skoog, F. A revised medium for rapid growth and bioassays with tobacco tissue cultures. Physiol. Plant. 1962, 15, 473-497. [CrossRef]

60. Slinkard, K.; Singleton, V.L. Total phenol analysis: Automation and comparison with manual methods. Am. J. Enol. Viticult. 1977, 28, 49-55.

61. Zengin, G.; Sarikurkcu, C.; Aktumsek, A.; Ceylan, R.; Ceylan, O. A comprehensive study on phytochemical characterization of Haplophyllum myrtifolium Boiss. endemic to Turkey and its inhibitory potential against key enzymes involved in Alzheimer, skin diseases and type II diabetes. Ind. Crop. Prod. 2014, 53, $244-251$. [CrossRef]

62. Zengin, G.; Uysal, A.; Diuzheva, A.; Gunes, E.; Jekő, J.; Cziáky, Z.; Picot-Allain, C.M.N.; Mahomoodally, M.F. Characterization of phytochemical components of Ferula halophila extracts using HPLC-MS/MS and their pharmacological potentials: A multi-functional insight. J. Pharm. Biomed. Anal. 2018, 160,374-382. [CrossRef]

63. Uysal, S.; Zengin, G.; Locatelli, M.; Bahadori, M.B.; Mocan, A.; Bellagamba, G.; De Luca, E.; Mollica, A.; Aktumsek, A. Cytotoxic and enzyme inhibitory potential of two Potentilla species (P. speciosa L. and P. reptans Willd.) and their chemical composition. Front. Pharmacol. 2017, 8, 290. [CrossRef] [PubMed]

Publisher's Note: MDPI stays neutral with regard to jurisdictional claims in published maps and institutional affiliations.

(C) 2020 by the authors. Licensee MDPI, Basel, Switzerland. This article is an open access article distributed under the terms and conditions of the Creative Commons Attribution (CC BY) license (http://creativecommons.org/licenses/by/4.0/). 